Juarez da Silva Bochi

\title{
Programação Paralela no Banco de Dados Chave-Valor Redis
}

Dissertação apresentada ao Programa de Pós-graduação em Informática do Departamento de Informática do Centro Técnico Científico da PUC-Rio como requisito parcial para obtenção do grau de Mestre em Informática.

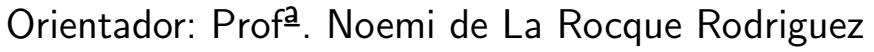




\title{
Juarez da Silva Bochi
}

\section{Programação Paralela no Banco de Dados Chave-Valor Redis}

Dissertação apresentada ao Programa de Pós-graduação em Informática do Departamento de Informática do Centro Técnico Científico da PUC-Rio como requisito parcial para obtenção do grau de Mestre em Informática. Aprovada pela Comissão Examinadora abaixo assinada.

\author{
Profa ${ }^{-}$. Noemi de La Rocque Rodriguez \\ Orientador \\ Departamento de Informática — PUC-Rio
}

Prof. Roberto lerusalimschy Pesquisador - PUC-Rio

Profa . Ana Lúcia de Moura Pesquisador - PUC-Rio

Prof. Prof. José Eugenio Leal

Coordenador Setorial do Centro

Técnico Científico - PUC-Rio 
Todos os direitos reservados. É proibida a reprodução total ou parcial do trabalho sem autorização da universidade, do autor e do orientador.

\section{Juarez da Silva Bochi}

Graduou-se em Engenharia Elétrica pela Universidade Federal do Rio grande do Sul (UFRGS). Atualmente trabalha com desenvolvimento de software na Globo.com.

Ficha Catalográfica

Bochi, Juarez da Silva

Programação Paralela no Banco de Dados Chave-Valor Redis / Juarez da Silva Bochi; orientador: Noemi de La Rocque Rodriguez. - 2015.

$62 \mathrm{f}$ : : il. (color); $30 \mathrm{~cm}$

1. Dissertação (mestrado) - Pontifícia Universidade Católica do Rio de Janeiro, Departamento de Informática, 2015.

Inclui bibliografia.

1. Informática - Teses. 2. Redis. 3. Lua. 4. Programação Paralela. 5. Modelos de Concorrência. 6. Modelo M:N. 7. Bancos de Dados. I. Rodriguez, Noemi de La Rocque. II. Pontifícia Universidade Católica do Rio de Janeiro. Departamento de Informática. III. Título. 


\section{Agradecimentos}

À globo.com, pelo apoio financeiro.

Aos professores e colegas da PUC-Rio, por todos os ensinamentos.

A todos meus amigos e familiares, pela amizade.

Aos amigos Leandro Ribeiro e Jean Emer, pela ajuda na revisão do texto.

À minha orientadora Noemi, pela inspiração, paciência e incentivo.

À Isabela, minha melhor amiga e companheira, por toda compreensão e carinho. 


\section{Resumo}

Bochi, Juarez da Silva; Rodriguez, Noemi de La Rocque. Programação Paralela no Banco de Dados Chave-Valor Redis. Rio de Janeiro, 2015. 62p. Dissertação de Mestrado - Departamento de Informática, Pontifícia Universidade Católica do Rio de Janeiro.

Redis é um banco de dados chave-valor de código livre que dá suporte à avaliação de scripts Lua, mas sua implementação utiliza apenas uma tarefa de sistema operacional. Scripts longos são desencorajados porque a avaliação do código é bloqueante, o que pode causar degradação de desempenho para os demais usuários. Através da aplicação do modelo de concorrência $M: N$, que combina tarefas de nível de sistema operacional com tarefas do nível de usuário, adicionamos no Redis a capacidade de execução de scripts em paralelo, permitindo que todos os núcleos do servidor sejam explorados. Com a utilização de corotinas Lua, implementamos um escalonador capaz de alocar e suspender a execução de tarefas de nível de usuário nos núcleos disponíveis sem necessidade de alteração do código dos scripts. Este modelo permitiu proteger o programador das complexidades naturais do paralelismo como sincronização no acesso a recursos compartilhados e escalonamento das tarefas.

\section{Palavras-chave}

Redis; Lua; Programação Paralela; Modelos de Concorrência; Modelo M:N; Bancos de Dados. 


\section{Abstract}

Bochi, Juarez da Silva; Rodriguez, Noemi de La Rocque (Advisor). Parallel Programing in the Redis Key-Value Datastore. Rio de Janeiro, 2015. 62p. MSc. Dissertation — Departamento de Informática, Pontifícia Universidade Católica do Rio de Janeiro.

Redis is an open source key-value database that supports Lua programming language scripts, but it's implementation is single threaded. Long running scripts are discouraged because script evaluation is blocking, which may cause service levels deterioration. Applying the $M: N$ threading model, which combines user and operating system threads, we added to Redis the ability of running scripts in parallel, leveraging all server cores. With the use of Lua coroutines, we implemented a scheduler able to allocate and suspend user-level tasks in the available cores without the need of changing scripts' source code. The M:N model allowed us to protect the programmer from the natural complexities that arise from parallel programming, such as access to shared resources synchronization and scheduling of tasks into different operational system threads.

\section{Keywords}

Redis; Lua; Parallel Programming; Threading models; M:N threading model; Databases. 


\section{Sumário}

1 Introdução $\quad 10$

2 Modelos multi-tarefa $\quad 12$

2.1 Motivação 12

2.2 Modelos de concorrência multi-tarefa 13

$\begin{array}{lll}2.3 \text { Conclusão } & 18\end{array}$

3 Redis e scripts Lua $\quad 19$

$\begin{array}{lll}3.1 & \text { Redis } & 19\end{array}$

3.2 Scripts Lua no Redis 21

3.3 Estados Lua para execução dos scripts 24

4 Concorrência de scripts Lua $\quad 27$

$\begin{array}{lll}4.1 & \text { Motivação } & 27\end{array}$

4.2 Interface para o usuário 28

$\begin{array}{lll}4.3 & \text { Implementação } & 29\end{array}$

4.4 Processamento de streams de dados 36

5 Resultados experimentais $\quad \mathbf{4 0}$

5.1 Execução de scripts de longa duração 41

5.2 Aceleração da execução de scripts 46

5.3 Processamento de dados em tempo real 48

6 Conclusão $\quad 52$

7 Referências Bibliográficas $\quad 54$

$\begin{array}{lll}\text { A Exemplo de sessão no terminal } & 58\end{array}$

B Algoritmo de quadratura adaptativa no Redis $\quad \mathbf{6 0}$ 


\section{Lista de figuras}

2.1 Evolução da frequência do clock de CPUs Intel, em MHz 12

3.1 Diagrama de sequência para execução do comando EVAL 25

4.1 Diagrama de sequência para execução do comando EVALASYNC 32

5.1 Comparativo de desempenho na multiplicação de matrizes, variando o tomanho da matriz

5.2 Desempenho na multiplicação de matrizes variando a quantidade de núcleos.

5.3 Comparação de desempenho no cálculo de integral definida. 47

5.4 DAG para contagem de hashtags 


\section{Lista de tabelas}

2.1 Comparação dos modelos de concorrência multi-tarefa 18

5.1 Comparação de desempenho de scripts bloqueantes 41 


\section{Introdução}

Existem poucos artigos na literatura que investigam modelos de paralelismo multi-core em linguagens dinâmicas (Skyrme et al., 2014). Normalmente, estas linguagens se limitam a expor a API de baixo nível do sistema operacional para criação de threads e processos, deixando o programador sujeito às armadilhas do compartilhamento de memória e à complexidade das primitivas de sincronização, como locks e semáforos. Este trabalho contribui com a análise e implementação do modelo multi-tarefa $M: N$, ou híbrido, para uma linguagem de script em uma aplicação real, com objetivo de contornar algumas destas dificuldades.

Mais especificamente, exploramos o modelo $M: N$, que combina tarefas de usuário e de sistema operacional, no banco de dados chave-valor Redis ${ }^{1}$, possibilitando a execução paralela de scripts Lua. Redis é um banco de dados em memória, single threaded, não relacional e de alto desempenho que suporta execução bloqueante de scripts Lua. Através da aplicação do modelo $M: N$, permitimos a execução paralela de scripts de uma forma que abstrai as complexidades do uso compartilhado de memória e do escalonamento de múltiplas tarefas. Nossas modificações da aplicação viabilizam o uso de todos os núcleos do servidor simultaneamente, através da execução em paralelo de múltiplos scripts, sem necessidade de modificação do código de scripts existentes.

A implementação padrão do banco de dados Redis não é multi-tarefa e portanto não há processamento paralelo de outros comandos durante a execução de qualquer comando ou script, mesmo que o servidor possua mais de um núcleo. Esta característica da implementação do Redis inviabiliza a execução de scripts de longa duração em cenários práticos com múltiplos clientes. Um único cliente executando scripts bloqueantes de longa duração pode degradar o atendimento dos demais clientes.

Implementamos o modelo multi-tarefa $M: N$ através da combinação de múltiplas threads de sistema operacional com corotinas Lua, de uma forma que possibilita a paralelização de scripts sem necessidade de modificação do

\footnotetext{
${ }^{1}$ http://redis.io
} 
código existente. Os scripts são executados sem bloquear os demais clientes e os núcleos extras do servidor são utilizados sem nenhuma alteração na semântica dos scripts para interação com o banco de dados. O escalonador implementado permite que os scripts de usuário sejam suspensos e retomados de acordo com a disponibilidade de núcleos e do banco de dados sem que o programador precise ceder explicitamente o controle da linha de execução ou que tenha que se preocupar com o uso de memória compartilhada.

Neste trabalho, descrevemos como implementamos este modelo e introduzimos novos comandos no banco de dados Redis para execução de scripts de maneira assíncrona compatível com os scripts não bloqueantes. A manutenção dos comandos para execução de scripts bloqueantes é justificada porque em alguns cenários é desejável que o código execute de maneira atômica. Também avaliamos a utilidade do sistema desenvolvido, através de aplicações reais criadas para explorar três grandes áreas de aplicação que visualizamos para nosso sistema:

- scripts de longa duração: São scripts que fazem alto uso de CPU e que não poderiam ser executados de forma bloqueante. Escolhemos desenvolver um sistema de detecção de anomalias e o implantamos para monitorar um datacenter com centenas de máquinas.

- aceleração de scripts: Neste cenário, o objetivo é diminuir o tempo de execução de uma tarefa explorando o paralelismo. Para representar um caso extremo deste tipo de aplicação, implementamos um algoritmo paralelo de quadratura adaptativa, que calcula a integral definida de uma função através da soma da área de trapézios.

- processamento em tempo real: Neste caso, desejamos processar um fluxo de dados contínuo sem bloquear o recebimento de informação. Para validar esta situação, criamos um detector de tópicos populares para a rede social Twitter.

Esta dissertação é dividida da seguinte maneira: O capítulo 2 expõe a motivação para se reavaliar os modelos de programação multi-tarefa e embasa a teoria por trás do modelo de paralelismo adotado. No capítulo 3, descrevemos o banco de dados Redis, a linguagem Lua e como o Redis a utiliza. No capítulo 4, apresentamos as modificações que foram feitas para aplicar o modelo $M: N$ na paralelização de scripts. O capítulo 5 apresenta as aplicações desenvolvidas e o resultado dos testes. Finalmente, no capítulo 6, encerramos com a conclusão. 


\section{2 \\ Modelos multi-tarefa}

\section{1}

\section{Motivação}

O "free-lunch" (Sutter, 2005) do aumento de velocidade de processamento através da aceleração do clock dos processadores acabou já há alguns anos. Conforme pode ser visto na figura 2.1 (McKenney, 2011), a frequência das CPUs está estagnada há mais de uma década. Desde o fim do aumento da frequência dos processadores, a aceleração de programas está condicionada ao bom aproveitamento de todos os núcleos disponíveis. A programação paralela é necessária e, apesar da dificuldade de se produzir código correto com compartilhamento de memória (Ousterhout, 1996), os programadores muitas vezes não possuem alternativas.

Figura 2.1: Evolução da frequência do clock de CPUs Intel, em MHz

Decompor tarefas em etapas que possam ser executadas em paralelo é uma das fontes de complexidade essencial (Brooks Jr., 1987) da programação paralela. Outra fonte de complexidade, acidental, da programação paralela é a criação e alocação destas subtarefas em múltiplas tarefas de sistema 
operacional. Este mapeamento de atividades em diferentes tarefas de sistema operacional é necessário para que haja paralelismo e aproveitamento dos vários núcleos do computador, uma vez que cada tarefa de sistema operacional não roda em mais de um núcleo simultaneamente. Este escalonamento exige muitos cuidados para uma implementação eficiente e correta. O acesso a recursos compartilhados, como memória e execução de operações de E/S, introduz dificuldades para o programador. A adoção de certos modelos de programação, linguagens ou bibliotecas pode auxiliar nestas dificuldades.

Neste capítulo, analisaremos os modelos de concorrência multi-tarefa, comparando as vantagens e desvantagens de cada um quanto à facilidade de programação, capacidade de paralelismo e eficiência na criação e na troca de contexto entre tarefas. Também mencionaremos os padrões de implementação e as abstrações de linguagens mais comuns em cada modelo.

\section{2}

\section{Modelos de concorrência multi-tarefa}

Tarefas ou threads são linhas de execução ou sequências de instruções independentes, cada um com sua própria pilha de execução. Um escalonador, seja de sistema operacional ou no nível de usuário, pode alocar estas tarefas em um ou mais núcleos do processador. Geralmente, os modelos multi tarefa são classificados em tarefas no nível de sistema operacional, tarefas no nível do usuário e modelo híbrido. Descreveremos cada um destes modelos a seguir.

\subsection{1}

\section{O modelo 1: 1: tarefas de nível do sistema operacional}

O modelo predominante para concorrência é a criação de uma thread de sistema operacional para cada tarefa independente que se deseja criar. Por esta razão, esse modelo é conhecido como 1:1. Todas as tarefas são criadas, gerenciadas, sincronizadas e finalizadas pelo núcleo (kernel) do sistema operacional.

Este modelo é o de implementação mais simples para as aplicações, uma vez que a coordenação das threads é feita pelo sistema operacional. Outra vantagem deste modelo é que o sistema operacional pode alocar as threads em núcleos diferentes do computador, possibilitando que elas executem em paralelo. Quando uma thread executa uma operação bloqueante, o sistema operacional também pode suspender a tarefa e alocar outras threads para execução. A preempção, ato de suspender temporariamente uma tarefa para executar outra rotina, não necessita cooperação da tarefa. A pilha de execução 
da tarefa é mantida e a troca de contexto é feita de maneira transparente para a aplicação.

Uma das desvantagens deste modelo está no custo relativamente alto de criação e troca de contexto entre threads. Geralmente, o modelo é vantajoso quando é necessário criar um pequeno número de threads independentes que rodem por longos períodos (McCracken, 2002). Além disto, este modelo clássico de programação multi-tarefa com preempção expõe o programador a algumas armadilhas. A combinação da preempção com o compartilhamento de memória é perigosa e requer o uso de primitivas de sincronização como locks e semáforos para o funcionamento correto da aplicação. O domínio desses mecanismos é raro entre programadores de aplicações, que são forçados a lutar contra deadlocks, condições de corrida e não determinismo.

Existem algumas abstrações e primitivas de linguagem que amenizam as dificuldades do paralelismo tradicional multi-tarefa com compartilhamento de memória. Estruturas de dados atômicas, como as presentes na linguagem Java, permitem que variáveis sejam compartilhadas sem a necessidade do controle de exclusão mútua manual. O uso de memória transacional (Herlihy et al., 2003) é outra maneira de se executar código de forma que outras tarefas não consigam ver estados intermediários, permitindo o compartilhamento de variáveis sem necessidade de sincronização. A implementação de memória transacional por software permite que isto seja feito em hardware comum e está disponível, por exemplo, na linguagem Clojure (Hickey, 2008). Passagem de mensagens e suas abstrações, como canais sequenciais (Hoare, 1978), implementados na linguagem $\mathrm{Go}^{1}$, e os atores de Erlang (Virding et al., 1996) e Scala (Haller e Odersky, 2007) também evitam a necessidade de sincronização ao eliminar o compartilhamento de memória. Estes recursos não são tão comuns em linguagens dinâmicas. Além disso, interpretadores de algumas destas linguagens, como Python e Ruby, utilizam um lock global do interpretador (GIL, do inglês Global Interpreter Lock). Este mecanismo de sincronização é adotado para proteger estruturas internas da linguagem, como aquelas usadas para gerenciamento de memória, que não são thread-safe ${ }^{2}$. Isto acaba dificultando a obtenção de paralelismo nestas linguagens.

O padrão de projeto thread pool evita o alto custo de criação e destruição de tarefas do modelo 1: 1. Este padrão é bastante comum e está disponível na linguagem Java, como uma das classes de Executors. A aplicação inicializa um conjunto de trabalhadores (workers) e envia tarefas (tasks) para estes trabalhadores através de uma fila. Cada worker é associado a uma thread

${ }^{1}$ http: //golang.org/

${ }^{2}$ https://wiki.python.org/moin/GlobalInterpreterLock 
de sistema operacional e pode, portanto, executar trabalho em paralelo. As tarefas (tasks), neste caso, não devem ser confundidas com tarefas (threads) de sistema operacional ou de usuário. Elas não possuem pilha própria de execução e são sempre executadas atomicamente, do início até o fim. Ao contrário de threads, que podem sofrer preempção pelo sistema operacional, o worker não pode suspender estas tarefas temporariamente para execução de outra tarefa. Portanto, embora o número de tarefas possa superar o número de trabalhadores neste padrão, como as tarefas não possuem linha de execução própria, o padrão de thread pool não foge do modelo 1: 1. De qualquer forma, o padrão é bastante útil e abstrai boa parte da complexidade do escalonamento de tarefas para o programador.

\subsection{2}

\section{O modelo $N: 1$ : tarefas de nível de usuário}

Neste modelo, a aplicação faz o escalonamento das tarefas e as tarefas não são sequer identificadas pelo sistema operacional. O modelo se chama $N: 1$ porque a aplicação executa $N$ tarefas de nível de usuário em uma única thread de sistema operacional. As tarefas são gerenciadas no nível de usuário e o sistema operacional enxerga apenas um processo monolítico. Sendo assim, este estilo é o mais portátil, uma vez que não depende do kernel do sistema operacional. Apesar do escalonamento ser uma complexidade adicional para a aplicação, o escalonador pode ser otimizado de acordo com as necessidades da aplicação, ao invés de se contar com um escalonador genérico como é o do sistema operacional.

Outra diferença neste modelo é que as threads precisam ceder explicitamente o controle, já que não é possível implementar preempção no nível de usuário. Tipicamente se tem um custo inferior de criação de novas tarefas e a troca de contexto é mais barata, porque não há necessidade de se entrar em modo privilegiado do kernel. A falta da preempção traz a grande vantagem de se eliminar a necessidade de sincronização. Neste modelo de programação multi tarefa não preemptiva ou colaborativa, só há troca de contexto quando uma linha de execução cede explicitamente o controle. A troca de contexto é determinística e em pontos pré-definidos nas tarefas de nível de usuário. Portanto, não há necessidade de sincronização adicional através de locks ou semáforos.

Como desvantagem, já que o sistema operacional vê uma única thread, não é possível rodar paralelamente tarefas distintas em núcleos diferentes do processador. Outra desvantagem é que toda a aplicação é bloqueada caso uma tarefa execute uma operação bloqueante, por exemplo, uma operação de E/S. Desta forma, operações bloqueantes precisam ser emuladas com operações não 
bloqueantes, o que nem sempre é possível (McCracken, 2002). Esta emulação deve ser feita pela aplicação, o que é um ônus para o programador. Ao utilizar uma biblioteca externa, por exemplo, ele precisa se certificar de que ela não é bloqueante. Mesmo que a biblioteca seja capaz de fazer operações de forma assíncrona, deve fazer isto de forma compatível com o escalonador da aplicação.

Devido a estas restrições, este modelo é bastante explorado em conjunto com a orientação a eventos, que tipicamente utiliza operações de entrada e saída não bloqueantes. Ao invés de se bloquear o fluxo de execução durante uma destas operações, um loop principal da aplicação executa continuamente e toda vez que uma operação de E/S é necessária, uma função de retorno (callback) é registrada para ser executada assincronamente quando a operação for concluída. A cada iteração do loop principal, o sistema operacional é consultado para que se determine as operações concluídas e as funções de retorno (callback) são chamadas.

Do ponto de vista do programador, no entanto, é mais simples raciocinar sobre operações de E/S síncronas ou bloqueantes, já que a pilha de execução e o contexto são preservados, como se a operação fosse executada instantaneamente. O modelo de programação de eventos é menos natural (Behren et al., 2003) para o programador. A inversão de controle faz com que diversos blocos de callback sejam aninhados, com um efeito no código conhecido coloquialmente como "callback hell", ou gerenciamento manual da pilha (Adya et al., 2002). Abstrações como Futuros (Walker et al., 1990) e Promessas (Liskov, 1988), assim como o operador await do C\# (Microsoft, 2014), aliviam este problema, ao preservar a pilha de execução.

Corotinas, como as implementadas em Lua (Moura e Ierusalimschy, 2009), também permitem implementar o modelo de tarefas de nível de usuário com operações de E/S não bloqueantes, mas de forma mais natural para o programador. Uma corotina pode ceder o controle (yield) e manter o seu contexto e pilha de execução quando o controle lhe for devolvido. Para emular operações de E/S não bloqueantes, ao invés de registrar uma função de retorno, a corotina pode ceder o controle enquanto o resultado não estiver disponível. Através deste mecanismo, uma biblioteca de E/S pode expor uma API que faz yield automaticamente em todas as operações de forma transparente para o cliente, liberando a corotina para a troca de contexto sempre que necessário. Isto permite que o programador raciocine sobre seu código como se ele fosse executado sequencialmente e de maneira síncrona. 


\subsection{3}

\section{O modelo híbrido $M: N$}

Os modelos descritos anteriormente fazem o gerenciamento de tarefas de nível de sistemas operacional ou de nível de usuário. No modelo de threading híbrido, ou $M: N$, um escalonador de aplicação controla a execução de $M$ tarefas de nível de usuário em $N$ threads de nível de sistema operacional, com $M>N$. Este modelo é o mais flexível, combinando as vantagens dos dois modelos, mas é o de implementação mais complexa, já que depende do trabalho combinado do escalonador do sistema operacional e da aplicação. Além disso, reintroduz a necessidade de sincronização caso as tarefas de usuário façam uso de memória compartilhada. Como vantagens, combina os benefícios da velocidade e baixo custo de criação e troca de contexto das threads a nível de usuário com a possibilidade de execução em paralelo das threads de sistema operacional.

Scheduler Activations (Anderson et al., 1991) são um exemplo deste modelo, provendo threads de nível de kernel com flexibilidade de threads de usuário, escalonáveis pela aplicação. Esta estratégia foi adotada no sistema operacional NetBSD, mas abandonada devido à complexidade de implementação.

Um outro exemplo deste modelo é o mecanismo User-Mode Scheduling (Microsoft, 2014) introduzido no Windows 7. Este mecanismo permite que aplicações gerenciem o escalonamento de suas threads, cada uma com sua própria pilha de execução. Com a troca de contexto mais leve, há um aproveitamento mais eficiente dos processadores quando há um grande volume de tarefas, mas o desenvolvedor precisa implementar um escalonador próprio.

Os atores da linguagem Scala (Haller e Odersky, 2009), por combinarem primitivas de threads e de eventos, também podem ser vistos como exemplo do modelo $M: N$. Uma vantagem neste caso é que o escalonador é abstraído pela biblioteca da linguagem. Um ator pode suspender a pilha de execução ao invocar receive, como no modelo de threads, e manter a pilha ao invocar react, como no modelo baseado em eventos.

A biblioteca luaproc da linguagem de programação Lua (Skyrme et al., 2008) é outro exemplo deste modelo. A biblioteca implementa um escalonador que gerencia a execução de múltiplas tarefas criadas pelo usuário. Ao utilizar os comandos definidos pela biblioteca para troca síncrona de mensagem, as tarefas são automaticamente suspensas ou retomadas de acordo com a disponibilidade de executores e das mensagens, de forma transparente para o programador. A complexidade de implementação do modelo $M: N$ é abstraída para o programador, permitindo que ele se beneficie das vantagens do modelo: 
paralelismo multi tarefa, tarefas com baixo custo e simplicidade de raciocínio em cima do código propiciado pelo uso de corotinas.

\section{3}

\section{Conclusão}

Não podemos afirmar que algum dos modelos apresentados é superior aos demais. Cada um deles possui suas vantagens e desvantagens. Na tabela 2.1, resumimos as características de cada um dos modelos de concorrência multi-tarefa avaliados.

Tabela 2.1: Comparação dos modelos de concorrência multi-tarefa

$\begin{array}{lllll} & \text { Escalonador } & \text { Paralelismo } & \text { Custo tarefas } & \text { Preempção } \\ \mathbf{1}: \mathbf{1} & \text { Sistema operacional } & \text { Sim } & \text { Alto } & \text { Sim } \\ \text { N:1 } & \text { Usuário } & \text { Não } & \text { Baixo } & \text { Não } \\ \text { M:N } & \text { Híbrido } & \text { Sim } & \text { Baixo } & \text { Sim }\end{array}$

O modelo $M: N$ é ainda pouco explorado em relação a aplicabilidade e limites e nossa contribuição se dá na implementação deste modelo em um sistema real. Como veremos neste trabalho, apesar das dificuldades inerentes à implementação de um escalonador no nível da aplicação, através deste modelo, é possível criar um sistema que permite ao usuário explorar o paralelismo multicore com uma linguagem dinâmica sem sobrecarregar o programador com as complexidades naturais da preempção ou da programação orientada a eventos.

Nesta dissertação, descrevemos a implementação do modelo $M: N$ em um cenário controlado, onde só há um tipo de E/S. Alteramos o banco de dados Redis para permitir que scripts Lua executem de forma concorrente e paralela. Ao transformar os scripts em corotinas que cedem o controle de execução automaticamente ao acessarem o banco de dados e que retomam automaticamente quando o resultado está disponível, abstraímos as complexidades do escalonamento de tarefas para o programador. No capítulo seguinte, descreveremos o banco de dados Redis, sua implementação e relação com a linguagem de script Lua, antes de abordarmos as modificações realizadas. 


\section{Redis e scripts Lua}

\section{1} Redis

Redis é um banco de dados remoto chave-valor com armazenamento em memória. Frequentemente é visto como um servidor de estruturas de dados, por permitir operações eficientes em diversos tipos abstratos. O Redis é bastante popular em diversas áreas de aplicação, como principal meio de armazenamento ou como meio auxiliar mais rápido para outros bancos de dados (cache). Sua implementação é na linguagem $\mathrm{C}$ e é single-threaded. Isto é, atende todos os clientes com uma única thread de execução do sistema operacional através de uma arquitetura baseada em loop de eventos. É um servidor em rede, que recebe requisições de clientes através de uma porta TCP/IP ou de um Unix socket. Os comandos permitidos no Redis são abstrações simples que operam sobre cinco estruturas de dados: strings, listas, conjuntos, conjuntos ordenados e dicionários. Uma das características principais do servidor é a baixa latência, obtida principalmente pelo armazenamento principal em memória, sem garantia de durabilidade.

Existem duas formas opcionais de persistência no Redis ${ }^{1}$ : arquivo de journal em disco (AOF) e snapshots periódicos (RDB). Nenhuma dessas formas provê garantia total de durabilidade, já que os comandos dos clientes são avaliados e os resultados retornados para o cliente antes de serem salvos. Para manter o tempo de resposta baixo, o Redis não espera que uma operação seja escrita no arquivo de journal em disco para considerá-la executada. Isso significa que o Redis, assim como outros bancos de dados não relacionais (NoSQL), não dá suporte completo a transações ACID, porque não há garantia de durabilidade. Quando a funcionalidade de snapshot é ativada, os dados são gravados periodicamente de forma assíncrona em disco. Esta gravação do snapshot em disco é a única situação na qual a implementação padrão do banco de dados faz uso de outra thread de sistema operacional além da thread principal.

${ }^{1}$ http://redis.io/topics/persistence 
Para alta disponibilidade, um servidor Redis pode operar como réplica de um servidor mestre, agindo no modo escravo em hot stand-by (Tanenbaum e Steen, 2006). Neste caso, todos os comandos executados no mestre são replicados para o escravo. Para manter a latência de atendimento dos clientes baixa, o servidor mestre pode aceitar um comando e enviar a resposta para o cliente antes de o comando ser replicado para os escravos. Uma consequência negativa desta decisão é que, caso haja uma falha no servidor mestre, uma réplica poderá ficar desincronizada. Isto é, não há garantia de consistência entre as réplicas. Quado o Redis detecta a inconsistência do escravo, pode forçar uma re-sincronização total. Os servidores escravo também podem atender clientes, mas somente aceitam operações de leitura. Assim, também é possível melhorar o desempenho do sistema através da replicação ao se dividir a carga de leitura em múltiplos processos.

A última versão do Redis, 3.0, dá suporte a um modo de operação em cluster no qual o banco de dados opera com múltiplos servidores mestre que aceitam comandos de escrita, operando simultaneamente. Cada mestre pode ter uma ou mais réplicas. Se mais de uma réplica identificar que o mestre falhou, qualquer uma destas réplicas pode iniciar um processo de eleição. A réplica vencedora é então promovida para mestre. As chaves são fragmentadas entre os servidores através do algoritmo de consistent-hashing (Karger et al., 1997). Um cliente não precisa saber o nodo que contém a chave que deseja acessar. O cliente pode acessar qualquer servidor, mas, caso o servidor não seja responsável pela chave requisitada, o servidor retorna um erro para o cliente indicando qual outro nodo é responsável por esta chave. Deste modo, é possível armazenar mais conteúdo no sistema do que a memória disponível em um único servidor.

Por ser um banco de dados em memória com bom desempenho, o Redis é frequentemente utilizado como cache. É possível configurar um tamanho máximo de memória para o servidor e as políticas de liberação de memória. Por padrão, o algoritmo utilizado é uma aproximação de LRU (do inglês Least Recent Used, Menos Recentemente Utilizado), em que as chaves mais antigas, não acessadas há mais tempo, são apagadas primeiro.

O Redis dá suporte ao padrão de troca de mensagens PUB/SUB (do inglês Publisher/Subscriber, ou Publicador/Assinante). Neste padrão, ao invés de mensagens serem enviadas diretamente para receptores, publicadores enviam mensagens em tópicos e assinantes se inscrevem nos tópicos de interesse. Este padrão tem o benefício de desacoplar os remetentes dos destinatários, permitindo que publicadores possam enviar mensagem sem necessidade de conhecer os destinatários. Já os destinatários, isto é, assinantes de tópicos, não 
precisam conhecer todos os rementes e podem filtrar as mensagens de interesse de acordo com seus tópicos. Neste contexto, o Redis faz o papel de broker para troca das mensagens, recebendo as mensagens e repassando para os assinantes interessados. A implementação do banco não provê persistência das mensagens e somente os assinantes conectados recebem as mensagens publicadas, sem possibilidade de consultarem mensagens anteriores.

Como o banco de dados tem uma implementação single-threaded, os comandos do sistema não são executados de forma concorrente e são naturalmente serializados. Assim, há garantia natural de atomicidade, isolamento e consistência no sentido ACID de todas as operações executados no Redis, apesar de não haver garantia de durabilidade. Essas garantias são válidas inclusive no com o uso de scripts, códigos em Lua enviados pelos usuários.

O código Lua dos scripts é avaliado de forma bloqueante e atômica. Ou seja, o atendimento de outros clientes é suspenso enquanto um script está executando. O fato do Redis não permitir a execução paralela de scripts simplifica a implementação do servidor e também permite que scripts executem múltiplos comandos de maneira atômica. No entanto, este comportamento impossibilita a execução de scripts de longa duração em ambientes com múltiplos usuários. Mesmo que os scripts façam apenas operações de leitura, o atendimento dos demais usuários é interrompido durante a avaliação destes scripts, o que pode acarretar uma degradação inaceitável do serviço.

\section{2}

\section{Scripts Lua no Redis}

\section{Objetivo do suporte a scripts no Redis}

Desde a versão 2.6, o Redis dá suporte à execução de scripts Lua submetidos pelo cliente. O primeiro motivo ${ }^{2}$ para a introdução do suporte a scripts foi economia de banda e redução de latência. Muitas vezes, uma aplicação necessita executar múltiplos comandos para ler o banco de dados, processar alguma informação e escrever o resultado de volta no sistema. Este tráfego de ida e volta de dados entre o cliente e o servidor pode ser evitado ao se mover o processamento para o servidor, eliminando a latência do envio de múltiplos comandos e respostas na rede. Esta não é uma ideia nova e é largamente explorada em outros ambientes distribuídos, como por exemplo, no uso de stored procedures em bancos de dados relacionais.

O segundo motivo é que normalmente o gargalo do banco de dados Redis tende a ser E/S, não CPU. Mesmo nos casos em que a CPU é exigida, a maior

\footnotetext{
${ }^{2}$ http://oldblog.antirez.com/post/redis-and-scripting.html
} 
parte do uso de CPU geralmente está no processamento do protocolo de rede, não nas operações sobre as estruturas de dados. Desta forma, outro benefício da execução de scripts é amenizar o gargalo de E/S, já que a lógica da aplicação remota passa a ser executada no servidor, fazendo com que menos comandos tenham que ser transmitidos pela rede.

Por fim, o terceiro motivo da introdução dos scripts foi permitir a execução atômica de operações para as quais o Redis não provê um comando específico. Apesar de existirem mais de 150 comandos na última versão estável do Redis, praticamente todos são abstrações simples em cima das estruturas de dados disponibilizadas. Cada uma destas operações executa de forma atômica, mas de acordo com a necessidade da aplicação, é necessário compor múltiplos comandos do Redis. Para executar estes diversos comandos de forma atômica, antes da introdução dos scripts, era necessário utilizar transações, fonte de complexidade adicional do ponto de vista do programador. Os comandos para manipulação de transações ainda estão disponíveis no banco de dados, mas seu uso é desencorajado pela dificuldade de serem usados corretamente. O Redis considera que uma transação falhou, e a reverte, somente quando uma chave monitorada explicitamente é modificada durante a transação.

Para ilustrar a complexidade do uso de transações no Redis, mostramos a seguir o código em Ruby necessário para incrementar um contador apenas se ele existir. O teste de existência da chave é necessário porque o comando INCR cria a chave com valor 1 caso ela não exista.

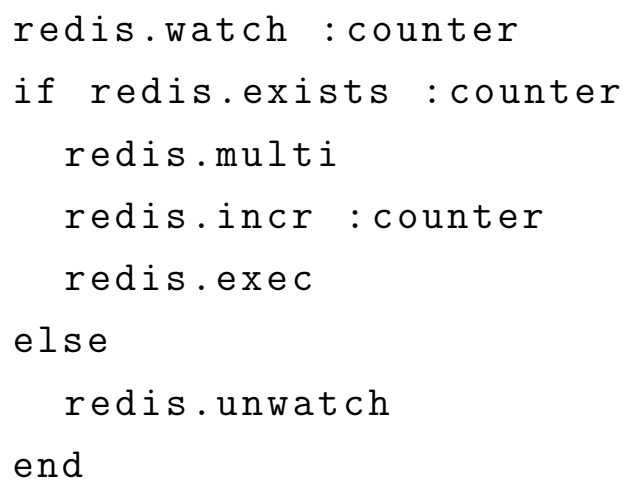

Este código, que utiliza os comandos WATCH, MULTI, UNWATCH e EXEC para controle da transação. Observamos que o comando UNWATCH não é necessário após o comando EXEC. Quando o comando EXEC é invocado, todas as chaves deixam de ser monitorados. Este código é equivalente ao seguinte script Lua:

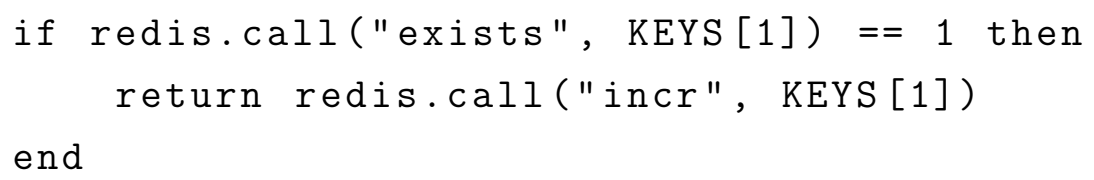


Com o uso de scripts, a combinação de comandos é muito mais simples, já que não há necessidade de se preocupar com condições de corrida. Os scripts são executados atomicamente, mesmo quando fazem chamadas a vários comandos. Desta forma, scripts podem ser vistos como comandos customizados, além dos nativos do servidor.

\section{Interface de execução de scripts para os clientes}

O Redis é um servidor acessível via rede e permite que clientes executem comandos $^{3}$ através de um protocolo próprio ${ }^{4}$. A implementação padrão do Redis também disponibiliza uma biblioteca para a construção de clientes com a linguagem $C$ e uma interface de linha de comando REPL (do inglês Read Eval Print Loop). Existem bibliotecas desenvolvidas por terceiros disponíveis para construções de clientes em diversas linguagens ${ }^{5}$.

O ponto de entrada para execução de scripts é um comando chamado EVAL que recebe como argumento o corpo de uma função Lua para execução. O Redis também permite que um script seja carregado e executado múltiplas vezes sem necessidade de reenvio do corpo da função Lua. Para isto, utiliza como identificador do script o hash SHA-1 do corpo da função. Não é permitido definir nomes para as funções. Abaixo, listamos todos comandos relacionados a scripting na implementação padrão:

EVAL script numkeys key [key ...] arg [arg ...]: Executa um script Lua no servidor. O comando recebe como argumentos o código do script, a quantidade de argumentos que são chaves do banco de dados, as chaves e demais argumentos para execução do script.

EVALSHA sha1 numkeys key [key ...] arg [arg ...]: Executa um script Lua pré-definido no servidor através dos comandos EVAL ou SCRIPT LOAD. Utiliza o hash SHA-1 do corpo do código do script como identificador e os demais argumentos são tratados como no comando EVAL.

SCRIPT EXISTS script [script ...]: Testa a existência de um script do servidor. Isto é, testa se ele já foi executado ou definido anteriormente.

SCRIPT FLUSH: Remove todos os scripts do cache do servidor

SCRIPT LOAD script: Define um script no servidor e retorna o seu identificador (hash SHA-1).

SCRIPT KILL: Interrompe a execução do script.

O apêndice A demostra uma sessão com estes comandos.

\footnotetext{
${ }^{3}$ http: //redis.io/commands

${ }^{4}$ http://redis.io/topics/protocol

${ }^{5}$ http://redis.io/clients
} 


\section{Interface com o banco de dados para os scripts}

Os scripts executados pelo Redis rodam em uma espécide de sandbox, com acesso restrito aos módulos padrão de Lua e sem direito de criar variáveis globais. O módulo os, por exemplo, não é disponibilizado para evitar que scripts acessem diretamente o sistema de arquivos. Os scripts têm acesso a um módulo exposto pelo banco de dados chamado redis. É este módulo que permite a interação com o banco de dados. As funções disponiblizadas por ele são:

- call, para execução de comandos Redis.

- pcall, para execução de comandos de modo protegido, retornando uma string com a descrição do erro em caso de falha.

- log, para mensagens de log.

- sha1hex, para cálculo do hash sha1.

- error_reply, para retorno de erro.

- status_reply, para retorno com status de sucesso.

\section{3}

\section{Estados Lua para execução dos scripts}

Lua é uma linguagem extensível, ou seja, é possível criar módulos em C que alteram o comportamento da linguagem. Também é uma linguagem de extensão, isto é, pode ser embutida em uma aplicação, permitindo que código em Lua amplie o comportamento da aplicação. De acordo com estas definições, Lua é usada no banco de dados Redis das duas maneiras, mas principalmente como uma linguagem de extensão da aplicação Redis. Apesar de expor aos scripts uma linguagem estendida com adição de bibliotecas, como, por exemplo, bibliotecas para manipulação de estruturas no formato json e msgpack e funções definidas em C para que os scripts possam interagir com a aplicação, os scripts são utilizados principalmente para estender o comportamento da aplicação.

Lua permite que múltiplos ambientes de execução, chamados de estados Lua, co-existam de forma isolada em uma mesma aplicação. Para que isso seja possível, Lua não mantém nenhuma variável ou estado global em variáveis da biblioteca. Todo estado é encapsulado em uma estrutura chamada lua_State e cada lua_Stat e possui uma thread Lua de execução com sua própria pilha de execução. A interação entre C e a API de Lua é feita principalmente através de uma pilha (stack) de valores. É possível criar threads Lua (não de sistema operacional) adicionais em um mesmo lua_St a te através do 
uso de corotinas, que possuem uma pilha de execução independente da thread Lua principal.

A implementação padrão de Redis cria um único estado Lua na sua inicialização e o utiliza para interpretar todos os comandos executados por quaisquer clientes. Cada script é criado como uma função global deste lua_State. É possível passar argumentos para os scripts através de dois tipos de variáveis: ARGV e KEYS. KEYS são argumentos especiais que devem ser utilizados para especificar as chaves do banco de dados que o script irá acessar. Quando em modo cluster, o sistema valida que as chaves passadas para o script através do argumento KEYS pertencem de fato ao servidor.

A linguagem Lua permite que variáveis globais sejam criadas dentro de funções. Para evitar que scripts interfiram uns com os outros através do uso compartilhado de variáveis globais, o Redis impõe uma restrição na criação destas variáveis. Esta restrição é criada através da modificação da metatable da tabela da variável de ambiente, impedindo a inserção de novas chaves nesta tabela.

A função call disponibilizada para os scripts é definida em C. Quando essa função é invocada pelo script, o sistema utiliza um cliente Redis virtual para execução do comando solicitado. Quando o resultado do comando é obtido, ele é convertido dos tipos nativos do Redis para um valor ou tabela Lua e finalmente retornado para o script. Quando o script retorna, os valores Lua retornados pelo script são serializados para o protocolo de rede e enviados para o cliente real que acionou a execução do script.

Figura 3.1: Diagrama de sequência para execução do comando EVAL.

A figura 3.1 é um diagrama do fluxo de execução de um script. Quando um usuário executa um comando EVAL, dispara um evento de E/S no Redis. O loop de eventos identifica que o comando é um comando de execução de script 
e aciona a função evalGenericCommand. Esta função prepara o script, definindo-o como uma função Lua, e insere os argumentos do script na pilha do estado Lua. O banco de dados inicia o script através da chamada da API Lua lua_call.

Para interagir com o banco de dados, o script invoca a função Lua redis.call, que, por sua vez, invoca a função $\mathrm{C}$ do Redis chamada luaredisCallCommand. Dentro desta função, o comando do banco de dados é executado e o resultado inserido na pilha do estado Lua. O resultado é sempre convertido para os tipos da linguagem. Como está ilustrado no diagrama, caso o retorno seja numérico, a conversão é feita através da função lua_pushnumber. A função C retorna então o controle para o estado Lua e o script prossegue a execução. O script pode fazer mais chamadas à função call, repetindo o ciclo.

Quando o script termina de executar, o controle retorna para a função evalGenericCommand. Esta função pega o resultado da pilha do estado Lua e o serializa para o protocolo Redis através da função luaReplyToRedisReply. Finalmente, o resultado é enviado via rede para o usuário. Durante todo este processo todos os usuários estão bloqueados e todas estas etapas são executadas de maneira síncrona. 


\section{Concorrência de scripts Lua}

\section{1}

\section{Motivação}

Apesar da implementação padrão de scripts do Redis atender bem todos os objetivos iniciais descritos na seção 3.2, ela apresenta algumas limitações. Como já mencionado, todos os clientes são bloqueados enquanto um script está sendo processado. Como consequência, não é recomendável executar scripts de longa duração. Em certos cenários, mesmo quando o tempo de execução ultrapassa poucos milisegundos, seja porque os scripts executam muitos comandos no Redis ou por que fazem uso intensivo de CPU, a degradação no atendimento dos demais clientes não é tolerável. É principalmente por este motivo que a empresa Twitter não utiliza scripts nas suas dezenas de milhares de instâncias do banco de dados Redis (Yue, 2014). A possibilidade de execução de scripts de forma não bloqueante é uma funcionalidade requisitada com certa frequência nos fóruns do banco de dados ${ }^{1}$. Um dos objetivos deste trabalho é atender esta demanda, introduzido comandos que permitem que o usuário execute scripts de forma não bloqueante. Do ponto de vista do cliente, o comando continua sendo executado de maneira aparentemente bloqueante, com a resposta sendo retornada depois de certo tempo. Isto continua sendo perfeitamente aceitåvel, no entanto, adicionamos a capacidade do servidor processar comandos de outros usuários neste período. Também adicionamos a capacidade de execução de múltiplos scripts em paralelo.

Em alguns casos, a atomicidade dos scripts pode ser desejada. O script pode precisar a garantia de que nenhum outro cliente alterará as chaves que está manipulando. Em outros casos, esta garantia não é necessária e pode ser vantajoso que a interação dos scripts com o banco de dados seja assíncrona, de forma concorrente com outros scripts e clientes para que o banco de dados seja liberado para processar outros comandos. Como existem estes dois cenários possíveis de uso, optamos por permitir que o usuário possa escolher se o script será avaliado com ou sem necessidade de atomicidade e isolamento, isto é, de

${ }^{1}$ https://groups .google.com/forum/\#! topic/redis-db/qIvehBvufLM 
forma síncrona ou assíncrona.

A utilização de scripts concorrentes traz o benefício adicional do aproveitamento dos múltiplos núcleos do servidor. Scripts que fazem grande uso de CPU podem ser executados no servidor, sem risco de impacto para outros usuários. O paralelismo pode ser obtido através da criação de várias tarefas de sistema operacional, que potencialmente podem executar scripts distintos. Os scripts em si podem ser vistos como tarefas de nível de usuário, podendo ser suspensos quando interagem com o banco de dados, liberando as tarefas de sistema operacional para o processamento de outros scripts. Esta implementação segue o modelo multi-tarefa $M: N$ e será discutida em detalhes na seção 4.3. $\mathrm{Na}$ seção a seguir, discutimos a interface para acionamento dos scripts.

\section{2}

\section{Interface para o usuário}

Disponibilizamos os seguintes comandos no banco de dados para que o usuário possa invocar scripts de forma assíncrona:

EVALASYNC script numkeys key [key ...] arg [arg ...]: Executa um script Lua de maneira assíncrona. Os argumentos são idênticos aos de seu par EVAL.

EVALSHAASYNC sha1 numkeys key $\left[\begin{array}{lll}\text { key } & \ldots\end{array}\right.$ arg $[\arg \ldots]$ : Executa um script Lua pré-definido no servidor de maneira assíncrona. Assim como seu par EVALASYNC, utiliza como identificador do script o hash SHA-1 retornado por SCRIPT LOAD.

Estes dois comandos são o ponto de entrada para as modificações desenvolvidas no Redis neste trabalho e têm comportamento muito similar aos seus pares EVAL e EVALSHA, já descritos na seção 3.2. A única diferença dos novos comandos é que sua execução é não bloqueante e a interação dos scripts com o banco de dados é assíncrona.

A execução é dita assíncrona em contraposição à execução bloqueante, que é síncrona. Quando um script é avaliado pelo comando EVAL, executa todos seus comandos de forma aparentemente instantânea, sem entrelaçamento com comandos de outros clientes. Na execução assíncrona, entre duas chamadas sucessivas do script para o banco de dados, comandos de outros clientes podem ser executados. Isto é, a execução de um script de forma assíncrona não é atômica e os comandos acionados por ele são executados de maneira entrelaçada com os comandos invocados por outros clientes.

Do ponto de vista do código, no entanto, as chamadas continuam aparentemente bloqueantes e síncronas. Quanto o script tenta interagir com o banco de dados, o escalonador suspende a execução do script e, quando o resultado 
está disponível, continua a execução, mantendo a mesma pilha de execução, mas sem, no entanto, bloquear o servidor. Do ponto de vista do cliente que aciona o script, também não há diferenças aparentes. O comando retorna o resultado depois que a execução termina. Não é possível para um cliente isolado executando comandos sequenciamente distinguir os scripts assíncronos dos comandos padrão do Redis.

Não introduzimos nenhuma alteração para um único script usufruir diretamente do assincronismo. Futuros (Walker et al., 1990), por exemplo, permitiriam a execução de múltiplos comandos em paralelo por um único script. Nosso objetivo foi manter a compatibilidade total com os scripts síncronos. Também optamos por não introduzir um modo híbrido de execução, em que apenas alguns trechos do código sejam executadas de forma síncrona. Este tipo de funcionalidade poderia ser útil, mas essa necessidade não surgiu durante o desenvolvimento das aplicacações do capítulo 5.

Outra decisão de projeto que tomamos foi não criar nenhuma interface para os scripts se comunicarem diretamente. Toda comunicação deve ser feita através do próprio banco de dados. Não vimos necessidade de os scripts trocarem mensagens porque o Redis já possui estruturas de dados de lista e canais PUB/SUB que podem ser usados como filas de mensagens. Através destas estruturas é possível fazer os scripts se comunicarem entre si ou com outros clientes do banco de dados.

Optamos também por não implementar compartilhamento de memória entre os scripts porque as chaves do banco de dados já fazem este papel naturalmente. O banco de dados provê os comandos necessários para acesso atômico às estruturas de dados que disponibiliza e assim evitamos a necessidade de sincronização explícita nos scripts, que seria necessária devido à existência de preempção de tarefas no modelo híbrido $M: N$. Sob o ponto de vista dos scripts, o banco pode ser considerado como uma espécie de tuple-space, através do qual os scripts podem interagir.

\section{3}

\section{Implementação}

Nossa implementação segue o modelo de threading híbrido $M: N$ descrito no capítulo 2. Cada script representa uma das $M$ tarefas de nível de usuário e criamos um pool de $N$ trabalhadores para executar estas tarefas. Cada worker é uma thread de sistema operacional e uma estratégia de escalonamento simples distribui as tarefas.

Na seção 3.3, vimos como os scripts são definidos e executados como funções em um estado Lua global na implementação padrão do Redis. As 
principais alterações que fizemos foram a criação de múltiplos estados Lua ao invés de um único estado global e a execução de scripts em corotinas ao invés de funções. As corotinas Lua (Moura e Ierusalimschy, 2009) são threads de nível de usuário com preempção colaborativa, o que permite suspender os scripts quando eles interagem com o banco de dados.

A linguagem Lua permite a criação de múltiplas corotinas em um estado Lua, possibilitando arquiteturas multitarefa sem preempção, isto é, modelo $N$ : 1. A execução de cada corotina Lua não pode ser feita por tarefas de sistema operacional distintas, mas a API em $\mathrm{C}$ da linguagem também permite que sejam criados múltiplos estados Lua isolados que podem executar em paralelo, desde que a execução de funções ou corotinas em cada estado seja iniciada por tarefas de sistema operacional diferentes. Como os estados são isolados, não há compartilhamento de variáveis e toda comunicação entre os estados deve ser intermediada pela aplicação. Utilizando esta API, bibliotecas podem implementar multithreading preemptivo. (Ierusalimschy, 2013) sugere uma implementação deste modelo utilizando troca de mensagens para comunicacão entre processos Lua. A biblioteca luaproc (Skyrme et al., 2008) é uma evolução desta implementação. Nossa implementação é bastante próxima à implementação da biblioteca luaproc. Nós criamos múltiplos estados Lua e um escalonador no nível de aplicação controla múltiplas tarefas de nível usuário, de acordo com o modelo $M: N$. Diferentemente da biblioteca luaproc, no entanto, na nossa implementação não há interação direta entre os estados Lua. A comunicação é feita sempre através do banco de dados.

A implementação padrão do Redis utiliza um loop de eventos que processa continuamente comandos invocados pelos clientes. Um script é tratado como um único comando, então o loop de eventos só trata qualquer outra requisição ao terminar de processar todo o script. Para permitir a execução de scripts de forma assíncrona, ainda dentro do loop de eventos, armazenamos qual foi o comando chamado (EVALASYNC ou EVALASHASYNC), assim como os argumentos do comando, em uma estrutura denominada task e a inserimos em uma fila global. A seguir, associamos um estado Lua à tarefa recém criada. Caso exista, utilizamos um lua_State livre e em caso contrário criamos um novo para execução do script.

Workers são criados na inicialização do banco de dados e buscam continuamente tarefas para execução da fila global. Quando um worker obtém uma tarefa da fila, executa a corotina que está definida no estado Lua até o script retornar o resultado ou tentar interagir com o banco de dados. Esta estratégia é similar ao padrão de thread pool; no entanto, neste caso, as tarefas podem ceder o controle e serem suspensas. Isto acontece quando o script tenta 
acessar o banco de dados através de uma chamada a call e o worker não consegue obter o lock global para execução do comando. Neste caso, o worker suspende a execução do script e reinsere a tarefa na fila global. Quando um worker obtém uma tarefa suspensa, adquire o lock para execução do comando do banco de dados e depois faz resume do lua_State, continuando a execução do script. Outras estratégias de escalonamento além da obtenção forçada do lock na segunda tentativa foram testadas, mas nos nossos testes tiveram desempenho inferior. Testamos, por exemplo, a criação de um worker exclusivo para interação com o banco de dados em uma fila independente.

Este lock global foi necessário porque as estruturas de dados internas do Redis não são thread-safe e por isso precisamos garantir que dois comandos não sejam executados simultaneamente. Se o loop de eventos tratasse a requisição de um cliente enquanto um script Lua executa um comando em outra thread de sistema operacional, as estruturas de dados do Redis poderiam ser corrompidas. Para fazer esta sincronização, usamos exclusão mútua entre os workers e o loop de eventos, que continua rodando em uma única thread de sistema operacional.

Também adicionamos exclusão mútua em algumas estruturas de dados globais, como seed de números aleatórios e horário do servidor. Outro ponto de sincronização necessário foi no buffer de escrita para os clientes. É feita exclusão mútua durante a serialização do resultado de cada script com o loop de eventos que envia o buffer para cada cliente. Com a ferramenta Valgrind ${ }^{2}$, certificamos que nenhuma outra estrutura de dados global poderia ser acessada em paralelo, gerando potenciais condições de corrida. A ferramenta verifica se endereços de memória compartilhada são acessados por threads distintas sem o uso de locks e também verifica se os locks são adquiridos e liberados na ordem correta.

Quando o script retorna um valor, serializamos o resultado e o enviamos para o cliente. A tarefa é então excluída e o estado Lua liberado para reutilização. A reutilização de estados Lua evita o custo relativamente alto de criação destas estruturas (Skyrme et al., 2008).

O diagrama da figura 4.1 resume como se dá a execução de um comando assíncrono. Diferentemente do diagrama da figura 3.1, a execução de lua_call é feita pelo worker, fora do loop de eventos principal. Adicionalmente, quando o script precisa interagir com o banco de dados ele cede a vez (yield) e o escalonador suspende sua execução. Quando o comando é executado por outro worker, o script é reiniciado. O passo a passo abaixo descreve este processo em maiores detalhes.

${ }^{2}$ http://valgrind.org/ 
1. Um cliente executa um comando EVALASYNC

2. O loop de eventos aciona uma função $\mathrm{C}$ responsável pelo comando, que lê o script e os argumentos passados pelo cliente (evalGenericCommand).

3. O banco cria uma task para o script e armazena os comandos passados pelo cliente

4. Worker obtém tarefa, define uma corotina Lua no lua_State e a invoca.

5. O script Lua invoca a função redis . call

6. O comando e os argumentos passados para a função redis . call são salvos. A função C redis . call retorna LUA_YIELD.

7. A função C que invocou o script Lua recebe como retorno LUA_Y IELD.

8. A tarefa é suspensa e reinserida no final da fila.

9. Um outro worker obtém a tarefa novamente.

10. O worker obtém o lock de exclusão mútua e executa o comando pendente.

11. O worker devolve o controle para a função C redis . call, retomando a corotina.

12. A função de continuação, finalmente converte o resultado para o Lua e devolve o controle para o script.

Figura 4.1: Diagrama de sequência para execução do comando EVALASYNC. 
13. Se o script invocar a função redis.call novamente, retorna para o passo 6.

14. O script termina, e o controle volta para a função $\mathrm{C}$ que invocou a corotina Lua.

15. O resultado é serializado e enviado para o cliente.

Nas subseções a seguir, descrevemos em maior detalhe alguns pontos que exigiram atenção para manter a corretude do banco de dados em todos os cenários.

\subsection{1}

\section{Encerramento do servidor}

Quando o servidor é encerrado ou quando um usuário executa o comando SCRIPT FLUSH, que limpa todos os scripts registrados, uma tarefa terminadora (poison pill) é inserida para cada worker existente. Quando um worker recebe uma destas tarefas especiais, ele encerra o Lua state e a pthread onde roda. Isto também garante que as tarefas assíncronas não serão interrompidas antes de retornarem e que nenhum comando EVALASYNC ficará pendente.

\subsection{2}

\section{Compartilhamento de scripts entre estados}

O Redis permite que um script seja carregado através do comando SCRIPT LOAD. Este comando retorna o hash SHA-1 do script como seu identificador. O script pode então ser avaliado através do comando EVALASHA. Internamente, na implementação padrão do Redis, quando um script é definido, o banco de dados cria uma função global no estado Lua com o identificador igual ao hash SHA-1 do seu código prefixado por f _. Quando o usuário invoca o comando EVALASYNCSHA, o banco verifica se a função com nome apropriado existe no estado Lua e então a invoca com os parâmetros fornecidos pelo usuário.

A introdução de múltiplos Lua States faz com que seja necessário definir o mesmo script em diferentes estados Lua. Quando o comando EVALA S YNCSHA é invocado e executado em um estado Lua diferente daquele em que o script foi definido a primeira vez, não basta testar se a função com o nome apropriado existe. Para contornar este problema, incluímos o seguinte passo na chamada de um script através de seu hash: quando a função não existe no Lua State, verificamos se o script existe no dicionário global dos scripts disponíveis. A implementação padrão mantém este dicionário para que novas réplicas do banco possam sincronizar os scripts existentes. Caso o script realmente 
esteja carregado, a função é re-definida no Lua State desejado. Existe uma necessidade de sincronização adicional para acesso deste dicionário, já que os workers só possuem controle de exclusão mútua na execução de comandos do banco de dados.

\subsection{3 \\ Replicação}

Vimos anteriormente que o Redis dá suporte à replicação para aumentar a disponibilidade do sistema. Neste modo de operação, uma única instância master recebe todas as escritas e envia para uma ou mais instâncias slave os comandos com argumentos que foram executados. A replicação é feita com a garantia de que os comandos serão executados na mesma ordem nas instâncias slave, de modo que todas sempre atinjam o mesmo estado final.

Na implementação padrão do Redis, os comandos síncronos EVAL e EVALSHA são replicados como comandos comuns. O próprio script e seus argumentos são re-interpretados nas réplicas. Para que isso não cause inconsistência no estado das réplicas, os scripts devem ser determinísticos, no sentido que, dado um estado inicial e os parâmetros de entrada, os scripts devem sempre fazer as mesmas operações, resultando em um mesmo estado final. É importante observar que todos os demais comandos do Redis são naturalmente determinísticos. Scripts que não executaram operações de escrita, assim como os comandos nativos de leitura, não são replicados porque não alteram este estado global. Diversas regras foram adicionadas ao banco de dados para tentar garantir a idempotência dos scripts:

- Não é permitido que scripts façam comandos de escrita depois de gerar um número pseudo-aleatório através da biblioteca random.

- Alguns comandos do Redis podem determinar que uma chave expire automaticamente depois de um certo intervalo de tempo, relativo à execução do script. Para que o tempo de processamento do script, que pode variar de uma máquina para outra, ou de uma execução para outra, não insira não determinismo, o horário de execução de cada comando é transferido entre a instância master e as réplicas. Além disso, todos os comandos invocados a partir do script são interpretados como se houvessem sido executados no mesmo timestamp de inicialização do script.

- Depois de executarem qualquer comando de escrita, os scripts não podem mais ser interrompidos através do comando SCRIPT KILL. 
Esta série de regras mostraram na prática ser suficientes para garantir a sincronização dos comandos bloqueantes, mas não são suficientes para garantir a replicação correta dos novos comandos EVALASYNC e EVALSHAASYNC. Como os comandos não são executados de maneira atômica, a concorrência introduz um não determinismo natural. Se um script estiver sendo executado concorrentemente com comandos ou scripts de outros clientes, a ordem em que os comandos do script e dos demais clientes será processada é indeterminada. Desta forma, a replicação do script na réplica não pode ser feita simplesmente reavaliando o script, já que o estado do sistema poderia ser alterado durante a execução do script.

Para ilustrar este problema, suponha o seguinte exemplo, que transfere 10 unidades da chave A para a chave B caso a chave A possua valor suficiente, isto é, maior que 10.

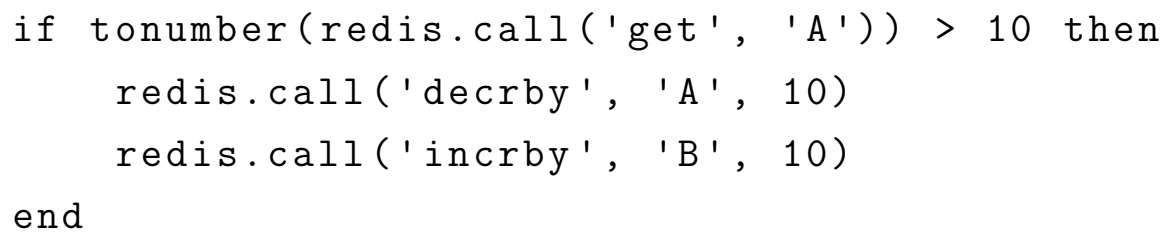

E um segundo script de define o valor de A como 0:

redis.call ('set', 'A', 0)

Se a variável A possuir o valor 10 e B possuir o valor 0 e os dois scripts forem invocados simultaneamente através do comando EVALASYNC, diversos estados finais (A, B) podem ser obtidos: $(0,0),(0,10)$ ou $(-10,10)$. Cada réplica poderia atingir um destes estados distintos, causando inconsistência entre elas.

Para fazer a replicação dos comandos de avaliação assíncrona de scripts deterministicamente, ao invés de executar os scripts nos slaves, ao invés de adicionarmos mais regras ou tentarmos contornar o problema, adotamos a solução mais simples e natural: replicamos as chamadas ao banco de dados na ordem em que são realizadas, independentemente do script de origem. Por exemplo, o servidor poderia enviar para a réplica a seguinte ordem de operações, ao invés dos dois scripts anteriores: SET A 0; DECRBY A 10; INCRBY B 10, resultando sempre no estado final (-10, 10). Esta solução é menos propensa a falhas que a solução adotada pela implementação padrão do banco de dados, mas é potencialmente mais cara, uma vez que uma quantidade grande de comandos pode ser executada por um script.

As restrições descritas acima foram criadas para garantir que as réplicas do banco atinjam o mesmo estado final após a execução dos scripts. Como fazemos a replicação da mescla de comandos executados por scripts assíncronos com os demais comandos executados na mesma ordem de entrelaçamento 
em que os comandos foram executados originalmente no servidor mestre, há garantia de que as réplicas sempre atingirão o mesmo estado final, sem necessidade de imposição das regras impostas para os scripts bloqueantes.

\subsection{4}

\section{Controle de timeout}

Como o servidor não executa outros comandos enquanto um script está sendo interpretado, o Redis oferece um mecanismo de timeout para que, caso um script demore muito para finalizar ou entre em loop infinito, se possa interromper a execução dele através do comando SCRIPT KILL.

Não estendemos essa funcionalidade de timeout para os scripts assíncronos, uma vez que eles não deixam o servidor ocupado. Também não estendemos o comando SCRIPT KILL para interrupção de comandos assíncronos devido à falta de uma forma de identificar cada script unicamente.

\subsection{5}

\section{Testes automatizados}

O Redis possui uma extensa suíte de testes de integração automatizados que verifica todo o comportamento funcional do banco de dados. Os testes são escritos na linguagem de programação TCL, que dá suporte à orientação a eventos. Processos servidores são criados e múltiplos clientes assíncronos executam comandos nestes servidores.

Tomamos a devida preocupacão de manter os testes existentes corretos e também adicionamos testes de integração adicionais para os comandos implementados. Basicamente, os novos testes verificam que os comandos EVALASYNC e EVALSHAASYNC se comportam corretamente de forma isolada e concorrente.

\section{4}

\section{Processamento de streams de dados}

A introdução da execução paralela de scripts no servidor abre a possiblidade de exploração de um outro paradigma, o de processamento de streams de dados em tempo real. Trabalhos recentes nesta área, como MillWheel (Akidau et al., 2013) e Storm (Toshniwal et al., 2014) permitem o processamento de um fluxo de informação através de grafos acíclicos direcionados (DAG, na sigla em inglês) de processamento. Os usuários destes sistemas podem especificar o código de execução de cada nó e a topologia do grafo. É possível criar um sistema equivalente, embora não distribuído, no Redis ao explorarmos o suporte 
do modelo PUB/SUB combinado com a avaliação de scripts Lua assíncronos introduzida neste trabalho.

Visualizamos cada script como um vértice da DAG de processamento. A comunicação entre scripts, representada pelas arestas do grafo, é feita através de canais PUB/SUB. Cada script pode ter múltiplas entradas, se inscrevendo (SUB) em múltiplos canais. As saídas são feitas através da publicação (PUB) por parte do script em um ou mais canais.

Na implementação padrão do Redis, scripts Lua já possuem a capacidade de publicar mensagens, da mesma forma que usuários comuns, através do comando PUBLISH, cujos parâmetros são o nome do canal e a mensagem. Qualquer usuário pode se increver em um canal através do comando SUBSCRIBE, que aceita como argumento o nome de um ou mais canais. O Redis se encarrega de republicar todas as mensagens recebidas para os assinantes incritos no canal. Depois de se inscrever em um canal, o cliente entra em modo assinante e passa a receber as mensagens assincronamente. O cliente em modo assinante não deve invocar mais comandos, a não ser comandos de inscrição ou desinscrição em canais.

Para construir o grafo de processamento que desejamos, é necessário garantir que as mensagens sejam entregues para todos os nós, mas a implementação padrão do Redis não provê esse tipo de garantia para os assinantes. Não há persistência das mensagens: clientes não podem recuperar mensagens que foram publicadas enquanto não estavam conectados. Este problema pode ser contornado ao se mover os assinantes para dentro do servidor. Scripts, no entanto, não podem se inscrever em canais na implementação padrão do Redis. Isto não foi implementado devido à incompatibilidade da natureza assíncrona do envio das mensagens e da execução síncrona e bloqueante dos scripts.

\subsection{1}

\section{Interface}

Com o suporte a scripts assíncronos que introduzimos neste trabalho, poderíamos permitir que scripts executassem o comando SUBSCRIBE e entrassem em modo assinante, recebendo as mensagens de forma assíncrona. Optamos, no entanto, por facilidade de uso e de implementação, em adicionar um comando para inscrever scripts em canais. O comando foi batizado como SSUBSCRIBE e permite inscrever um script como assinante de um canal. O banco de dados executa o script de forma assíncrona quando qualquer publisher publica uma mensagem no canal. Também adicionamos o comando SUNSUBSCRIBE para desinscrever scripts de canais. A listagem abaixo demonstra o uso destes comandos em uma seção no terminal. Os comandos são 
entrados após a seta $>$ e o símbolo $\hookrightarrow$ representa uma queda de linha.

Primeiramente, carregamos um script e recebemos o seu identificador SHA-1. O script incrementa a chave chamadas toda vez que é executado.

127.0.0.1:6379> SCRIPT LOAD 'redis.call ("incr", "chamadas") ' "c1f1242a3e4613130654d96ae85b88457d6ce4c8"

Verificamos então que o contador na chave chamadas não possui valor associado:

$127.0 .0 .1: 6379>$ GET chamadas

(nil)

Quando executamos o script pela primeira vez através do seu identificador, o valor da chave passa a ser 1 .

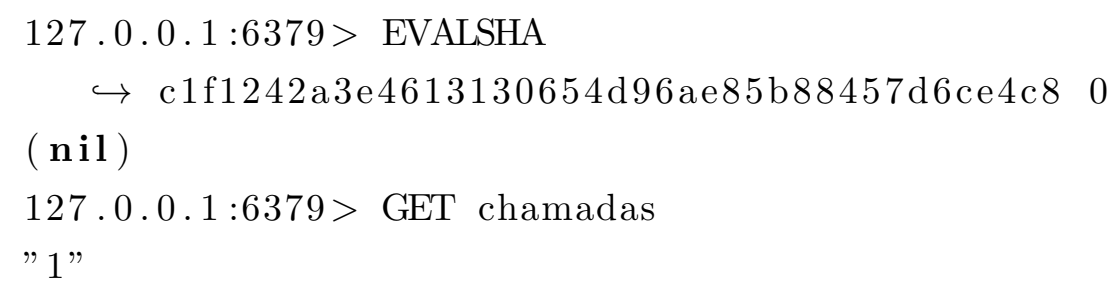

Inscrevemos então o script no canal channel.

$127.0 .0 .1: 6379>$ SSUBSCRIBE

$\hookrightarrow \mathrm{c} 1 \mathrm{f} 1242 \mathrm{a} 3 \mathrm{e} 4613130654 \mathrm{~d} 96 \mathrm{ae} 85 \mathrm{~b} 88457 \mathrm{~d} 6 \mathrm{ce} 4 \mathrm{c} 8$ channel OK

Quando publicamos a mensagem "message" neste canal, verificamos que o contador chamadas é incrementado.

127.0.0.1:6379> PUBLISH channel message

(integer) 1

127.0.0.1:6379> GET chamadas

$" 2 "$

Finalmente, desinscrevemos o script do canal e verificamos que o contador não é alterado, confirmando que o script não foi executado novamente.

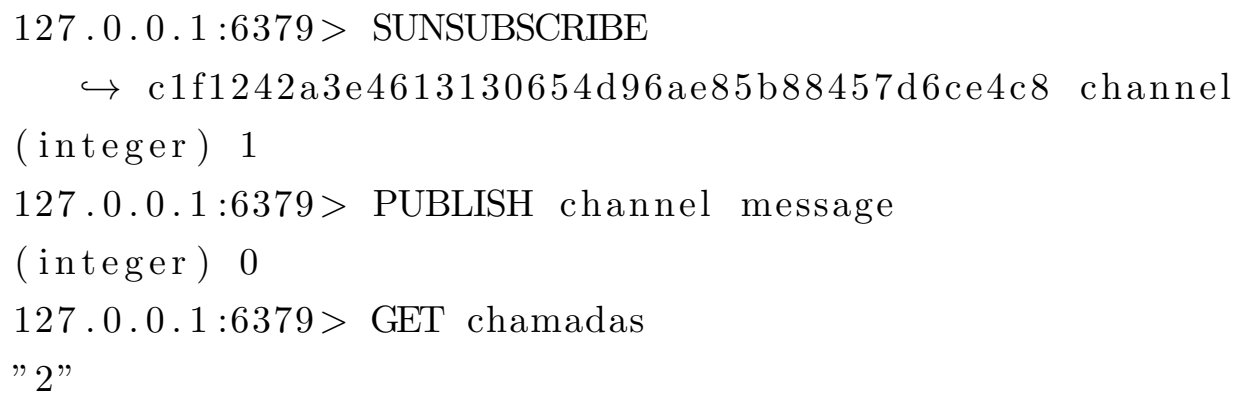




\subsection{2}

\section{Implementação}

A implementação destes dois novos comandos se resume a algumas alterações pontuais. Criamos um tipo novo de subscriber para representar scripts, ao invés de clientes na rede. Toda vez que um cliente publica uma mensagem em um canal que possui um assinante do tipo script, o banco de dados cria uma tarefa de execução assíncrona de scripts e a adiciona na fila para execução. O Redis executa o script passando como primeiro argumento o nome do canal e como segundo argumento a mensagem.

Como foi descrito nesta seção, através destes dois comandos, é possível construir grafo de processamento no Redis com Lua. Na seção 5.3, descrevemos uma pequena aplicação desenvolvida para validar este cenário de uso. 


\section{5 \\ Resultados experimentais}

Analisaremos os benefícios das modificações realizadas do ponto de vista de três cenários de uso:

- scripts de longa duração: São scripts que fazem alto uso de CPU e que não poderiam ser executados de forma bloqueante. Comparamos o desempenho da execução assíncrona com a implementação original na execução de um script para multiplicação de matrizes. Também desenvolvemos e avaliamos um sistema para detecção de anomalias.

- aceleração de scripts: Neste cenário, o objetivo é diminuir o tempo de execução de uma tarefa explorando o paralelismo. Para representar este tipo de aplicação, implementamos um algoritmo paralelo de quadratura adaptativa, que calcula a integral definida de uma função através da soma da área de trapézios.

- processamento em tempo real: Neste caso, desejamos processar um fluxo de dados contínuo sem bloquear o recebimento de informação. Para validar esta situação, criamos um detector de tópicos populares para a rede social Twitter.

As medidas de tempo de execução, exceto quando mencionado, foram realizados em uma instância do tipo c4.8xlarge da Amazon Web Services ${ }^{1}$. São máquinas virtuais com 36 vCPU Intel Xeon E5-2666 v3 (Haswell) de $2.9 \mathrm{GHz}$ e 60 Gb de memória RAM. O sistema operacional utilizado foi Amazon Linux AMI 2015.03², baseado em Red Hat 4.8.2-16. O Redis foi compilado com gcc 4.8.2 e utilizamos um pool de 15 workers $^{3}$ para tarefas assíncronas

\footnotetext{
${ }^{1}$ https://aws.amazon. com/ec2/instance-types/

${ }^{2}$ https: //aws. amazon.com/amazon-linux-ami/

${ }^{3}$ Como a máquina possui 36 núcleos virtuais, poderímos potencialmente executar até 35 workers em paralelo, mas optamos por manter alguns núcleos ociosos.
} 


\section{1}

\section{Execução de scripts de longa duração}

Scripts de longa duração bloqueiam o servidor, impedindo que outros clientes sejam atendidos. Neste primeiro cenário, temos por objetivo permitir que múltiplos scripts sejam executados em paralelo sem degradação significativa do atendimento dos demais clientes.

\subsection{1}

\section{Benchmark básico}

Nosso primeiro teste procura determinar qual a perda de desempenho devido ao custo adicional de sincronização que introduzimos para possibilitar a execução assíncrona. Executamos 10000 requisições através de 50 clientes concorrentes em cada teste através do comando de redis-benchmark da própria aplicação. O primeiro script representa um caso mínimo, que não interage com o banco e apenas retorna o valor 0 . O segundo script faz apenas uma chamada ao banco, incrementando um contador. Os resultados, medidos em milhares de requisições por segundo, estão relatados na tabela 5.1.

\begin{tabular}{llll}
\multicolumn{2}{c}{ Tabela } & 5.1 : Comparação de desempenho de scripts bloqueantes \\
Script & Implementação padrão & EVAL & EVALASYNC \\
Retorna 0 & $132 \mathrm{kreq} / \mathrm{s}$ & $114 \mathrm{kreq} / \mathrm{s}$ & $92 \mathrm{kreq} / \mathrm{s}$ \\
Incremento & $103 \mathrm{kreq} / \mathrm{s}$ & $101 \mathrm{kreq} / \mathrm{s}$ & $73 \mathrm{kreq} / \mathrm{s}$
\end{tabular}

Observamos um taxa de $14 \%$ inferior de requisições na utilização do comando EVAL no primeiro teste e $2 \%$ inferior no segundo. Esta perda de desempenho em relação à implementação padrão é devida aos mecanismos de sincronização introduzidos no loop de eventos da aplicação. Na utilização do comando asssíncrono, os números são respectivamente $31 \%$ e $29 \%$. A diferença na perda é levemente inferior $(2 \%)$ devido ao custo de criação e escalonamento das tarefas. Nestes casos extremos, não há nenhum ganho na utilização de scripts assíncronos.

Os benefícios da execução assíncrona são mais aparentes em casos mais típicos, em que os scripts fazem múltiplas chamadas ao banco de dados e utilizam mais CPU. Como exemplo mínimo deste caso, desenvolvemos um script para múltiplicar matrizes quadradas, que armazenamos em estruturas de dados de lista do Redis. Este exemplo pode parecer artificial, mas o armazenamento de grandes matrizes não é incomum no Redis. Na globo.com, uma estrutura similar é utilizada para armazenar a matriz de preferências de usuårios por vídeos (Pereira et al., 2014). O código está listado abaixo. 


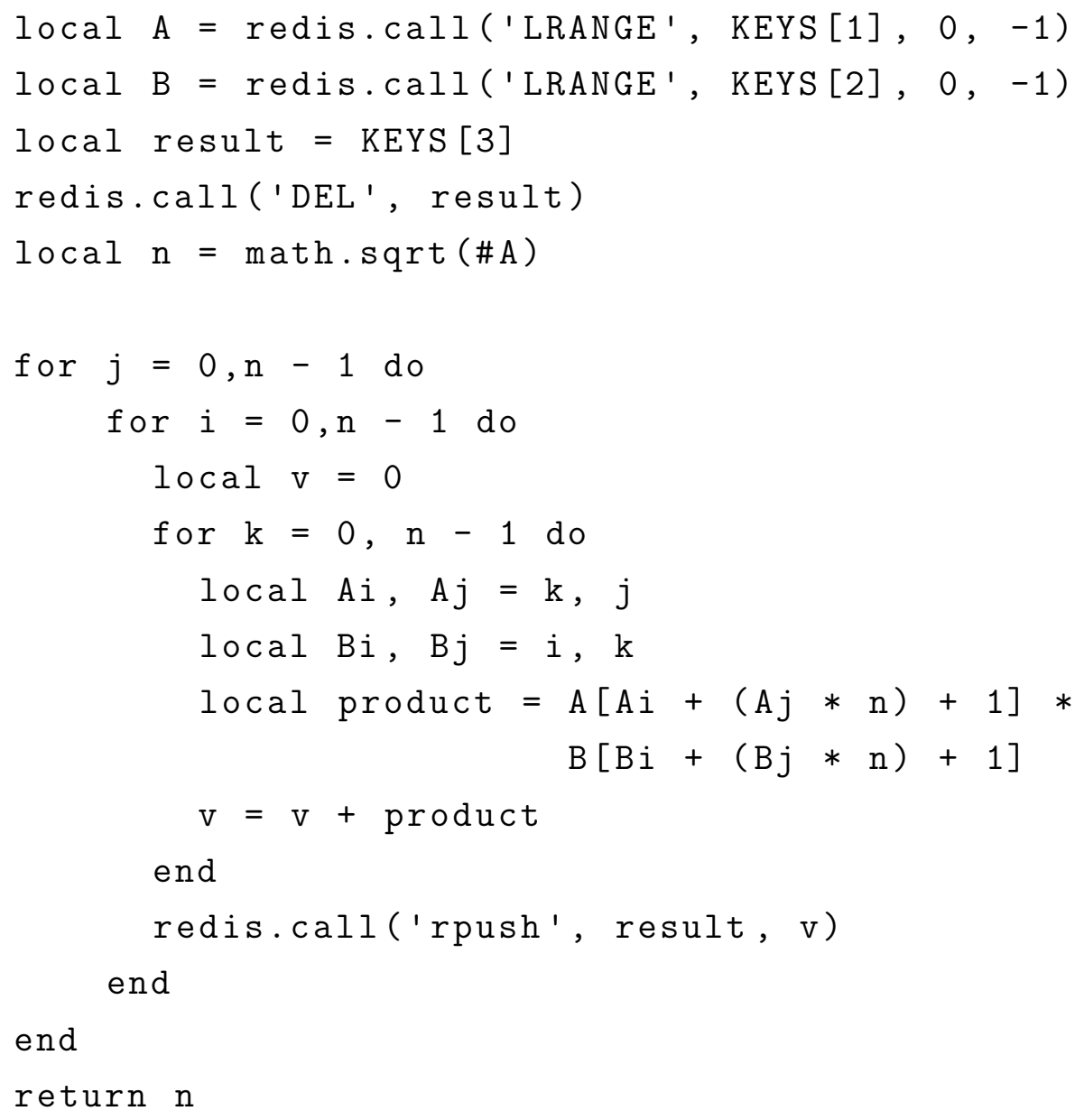

Executamos este script com o comando EVAL, com o comando EVALASYNC e com o comando EVAL na implementação padrão, sem nossas modificações. A figura 5.1 ilustra a quantidade de requisições por segundo, medida novamente com o aplicação redis - benchmark com 50 clientes paralelos, variando a dimensão das matrizes quadradas de 2 até 100. A diferença de desempenho entre o comando EVAL do Redis com nossas modificações e o da implementação padrão é de apenas $2.6 \%$ no pior caso e seria indistinguível no gráfico e por isso incluímos na figura apenas o desempenho dos comandos EVAL e EVALASYNC com nossas modificações. Para matrizes pequenas, o taxa de requisições por segundo atendida pelos comandos é similar (diferença abaixo de $5 \%$ para matrizes de dimensão 2). Quando o custo computacional cresce, com o aumento do tamanho das matrizes, a quantidade de requisições/s atendidas com o comando EVALASYNC passa a ser bastante superior $(9,5$ vezes maior para uma matriz de dimensão 100).

Na figura 5.2, plotamos a variação no número de requisições atendidas na múltiplicação de matrizes 100x100 à medida que se aumenta o tamanho do pool de threads. Observamos uma aceleração praticamente linear até 10 núcleos. 
Figura 5.1: Comparativo de desempenho na multiplicação de matrizes, variando o tomanho da matriz

\section{1 .2}

\section{Detecção de anomalia}

Os testes descritos na subseção anterior demonstram superioridade do comando EVALASYNC quando há uso de CPU significativo, mas em um exemplo artificial. Nesta subseção, discutiremos uma aplicação real desenvolvida para validar o caso de uso de scripts de longa duração no Redis. Implementamos um detector de anomalias em tempo real para séries temporais. A detecção de anomalias consiste em encontrar padrões de dados que não se encaixam no comportamento esperado e tem diversas aplicações, como detecção de intrusão e fraudes. Uma das grandes dificuldades da construção de um algoritmo para detecção de anomalias é que uma anomalia é, por definição, um comportamento inesperado. Isto torna o algoritmo difícil de ser treinado. Normalmente, utilizam-se métodos não supervisionados de treinamento (Chandola et al., 2009).

Nossa implementação foi desenvolvida visando a deteç̧ão de anomalias em datacenters. O algoritmo escolhido, no entanto, é genérico, e pode ser utilizado em outros contextos.

Abaixo, listamos algumas das dificuldades apresentadas na detecção de anomalias neste tipo de aplicação:

- O sistema deve ser capaz de armazenar um grande volume de informação: Datacenters comerciais frequentemente possuem milhares de servidores e cada servidor pode ser representado por uma série temporal multi- 
Figura 5.2: Desempenho na multiplicação de matrizes variando a quantidade de núcleos.

dimensional (CPU, uso de memória, etc). Devido à sazonalidade natural da utilização das aplicações em um data center, que pode variar de acordo com a hora do dia ou com o dia da semana, se requer que pelo menos o período de algumas semanas seja armazenado. Sendo assim, o volume total de dados coletados pode facilmente chegar na ordem de milhões de pontos.

- Os algoritmos para detecção de anomalia confiáveis exigem um esforço computacional razoável, mas com um baixo tempo de resposta.

- O processamento para detecção de anomalias não pode aumentar significativamente a latência da inserção de métricas.

\section{Implementação}

Construímos uma aplicação para demonstrar como nossa modificação do Redis é capaz de satisfazer esse conjunto de requisitos. O código desta aplicação está disponível em https://github.com/jbochi/mgof. Embora a aplicação seja compatível com a implementação padrão do Redis, que permite a coleta e armazenagem de um grande volume de métricas com uma baixa latência, quando alguma série temporal é processada em busca de anomalias, o bloqueio durante a execução do script impacta na latência da aplicação para coleta de dados. Só é praticável utilizar esta aplicação com a nossa versão de Redis com suporte a scripts concorrentes. 
Apesar do alto volume de informação que necessita ser armazenado pelo sistema, os clientes da aplicação estão tipicamente interessados em saber apenas se existe uma anomalia ou não em uma dada métrica ou servidor. Uma aplicação externa ao banco de dados necessitaria acessar toda a série temporal para fazer o processamento dos dados, mas os scripts Lua permitem que esse grande volume de informação seja processado, retornando uma resposta sumarizada (presença de anomalia ou não). Isto minimiza o tráfego de dados na rede. Nossa modificação do Redis permite que isto seja feito de forma não bloqueante, não interferindo na coleta de dados.

O algoritmo escolhido (Wang et al., 2011) para nossa implementação divide a série temporal em um conjunto de janelas de tempo configurável. Cada valor da série é dividido em um número também configurável de faixas, por padrão 10. Para se detectar a presença de anomalia na janela de tempo atual, o algoritmo compara a distribuição dos pontos em cada faixa na última janela com as distribuições das janelas anteriores. A janela é considerada anômala se sua distribuição não puder ser estatisticamente "explicada" pela distribuições anteriores através de um teste de chi quadrado.

A interface da aplicação tem apenas duas entradas. A primeira é a função de inserção de um ponto, que recebe como argumentos métrica, valor e timestamp. A segunda, detecção de anomalia, recebe como único argumento o nome da métrica e retorna se a anomalia está presente ou não. A detecção de anomalia também aceita parâmetros opcionais de configuração, como tamanho das janelas, número de faixas para classificação dos valores da série e nível de confiança mínimo para indicar que uma anomalia está presente.

Para executar a detecção da anomalia, registramos no banco de dados um script que aceita como argumento a métrica a ser analisada. Este script verifica o valor máximo e mínimo da série e classifica os pontos da última janela no número de faixas configurado. A seguir, calcula a distribuição dos pontos nessas faixas e compara essa distribuição com a distribuição das janelas anteriores. Para evitar que a distribuição de cada janela tenha que ser recalculada, o script armazena a distribuição de cada janela e a quantidade de vezes que cada janela foi utilizada para classificar outras janelas. Quando a janela atual tem uma distribuição similar à distribuição ocorrida em um número mínimo de janelas, o script retorna que a janela atual não é anômala. A quantidade de vezes que uma distribuição deve ocorrer para ser considerada normal também é configurável e por padrão é 1. Quando não existe uma distribuição anterior similar, o script retorna que a anomalia foi detectada.

Escolhemos armazenar as séries temporais como conjuntos ordenados do Redis. Cada elemento do conjunto possui um score que é utilizado 
na ordenação dos elementos. Utilizamos como score da série temporal o timest amp da métrica. O valor de cada elemento do conjunto deve ser único. Por isso, utilizamos como valor uma tupla com o timestamp e valor da métrica. No Redis, não existe uma outra estrutura ordenada, como uma fila, que permita valores duplicados.

\section{Resultados}

Implantamos esta aplicação para monitorar um conjuntos de poucas centenas de instâncias de bancos de dados utilizados no portal globo.com. Utilizamos como métricas a porcentagem de uso de CPU e de memória de cada instância de banco de dados. Durante nossos testes, identificamos uma instância que estava operando de forma anômala antes de qualquer incidente ser relatado, comprovando a eficácia do algoritmo.

Em termos de desempenho, a aplicação analisa uma janela de uma hora de uma série temporal de um mês, com um ponto a cada minuto, em 530ms em um laptop de uso pessoal ${ }^{4}$. A aplicação mantém em cache computações intermediárias e requisições subsquentes são processadas em 90ms, em média. Embora sejam tempos relativamente baixos, não é apropriado bloquear o servidor por períodos tão longos caso se esteja monitorando muitas séries temporais distintas.

\section{2}

\section{Aceleração da execução de scripts}

Neste caso, temos como objetivo a aceleração da execução de um script individual. O objetivo é dividir a tarefa e executar diversos scripts em paralelo ao invés de um único script sequencial com objetivo de diminuir o tempo total de execução. Para simular este cenário, implementamos um algoritmo de quadratura adaptativa (Andrews, 1991), que aproxima a integral de uma função através da soma da área de trapézios. Este não é um caso de uso real de aceleração de scripts no Redis porque não há necessidade de interação do script com o banco de dados. No entanto, é um algoritmo que exige muito processamento e por isso permite avaliar a possibilidade de aceleração de scripts e divisão de tarefas.

Inicialmente o algoritmo estima a integral da função como um único trapézio. Para verificar se a estimativa é adequada, o algoritmo divide o trapézio em dois e verifica se a nova estimativa está suficientemente próxima a anterior. Caso a diferença esteja acima da tolerância, subdivide o trapézio.

\footnotetext{
${ }^{4}$ Mac Book Pro Mid 2012 com 4 processadores 2.5 GHz Intel Core i5 e memória de 16 GB $1600 \mathrm{MHz}$ DDR3 e sistema operacional Mac OS X 10.10.3.
} 
O algoritmo é executado recursivamente para cada novo trapézio até se obter uma estimativa aceitável em todos os trapézios. Nossa implementação, listada no anexo $\mathrm{B}$, aceita que um ou mais scripts, com mesmo código, rode em paralelo. As regiões do gráfico que precisam ser subdivididas e recalculdas são armazenadas em uma fila compartilhada pelos scripts no Redis.

Para medir a real aceleração do algoritmo, também implementamos uma versão puramente sequencial em Lua, que não utiliza a fila no Redis e guarda a lista de regiões a ser calculada em memória. O tempo de execução deste código diretamente pelo interpretador Lua ou no Redis é aproximadamente igual e levemente inferior ao do script paralelo rodando em uma única thread, seja através do comando EVAL ou EVALASYNC. É claro que não é nosso objetivo acelerar algo que pode ser executado fora do banco de dados e esta medida foi tomada apenas para se verificar o custo da comunicação através do Redis.

Figura 5.3: Comparação de desempenho no cálculo de integral definida.

Os resultados estão apresentados na figura 5.3. Utilizando como referência o tempo de execução do script bloqueante, vemos que é possível acelerar a execução de um script através da utilização de múltiplos comandos em paralelo. Obtemos, inclusive, aceleração real do programa. Isto é, conseguimos um tempo de execução inferior ao melhor código sequencial fora do Redis. Este exemplo demonstra que a aceleração de scripts é viável dentro do banco de dados. 


\section{3}

\section{Processamento de dados em tempo real}

Para explorar o cenário de processamento de streams, criamos uma aplicação que contabiliza os hashtags mais populares na rede social Twitter. Nesta rede social, os usuários publicam mensagens de texto (ou tweets) de até 140 caracteres. Para facilitar a pesquisa e a descoberta de conteúdo, os usuários frequentemente marcam suas mensagens com hashtags. Estas etiquetas (tags) são palavras precedidas do caracter tralha (hash). O Twitter exibe na sua interface os tópicos mais comentados no momento de acordo com estes marcadores. Não é possível, no entanto, visualizar os tópicos mais comuns em uma dada região geográfica.

A rede social disponibiliza uma API para consumo de um canal com todos os tweets de uma região geográfica de interesse. Cada mensagem neste canal é composta pelo texto do tweet e por metadados, como localização e nome do usuário. Para processar esse stream de dados no Redis, criamos uma aplicação externa que se registra no stream do Twitter e publica todas as mensagens em um canal PUB/SUB do Redis.

O grafo de processamendo deste canal está descrito na figura 5.4. Nesta figura, os scripts estão representados como vértices com formato oval, os canais como arestas direcionadas e as chaves do Redis como retângulos.

O script "Conta mensagens" da figura 5.4 é carregado e inscrito no canal "twitter" através dos seguintes comandos:

SCRIPT LOAD "redis.call('incr', 'messages ')" SSUBSCRIBE e 2 e $5237 \mathrm{dbb} 8 \mathrm{a} 0827 \mathrm{abff} 6 \mathrm{e} 678 \mathrm{f} 2 \mathrm{f} 6 \mathrm{db} 0254$ e $77 \mathrm{f} 5$

$\hookrightarrow$ twitter

$\mathrm{OK}$

O script "Extrai texto", que cria um novo canal cujo conteúdo é apenas o texto das mensagens, sem seus metadados, é criado da seguinte maneira:

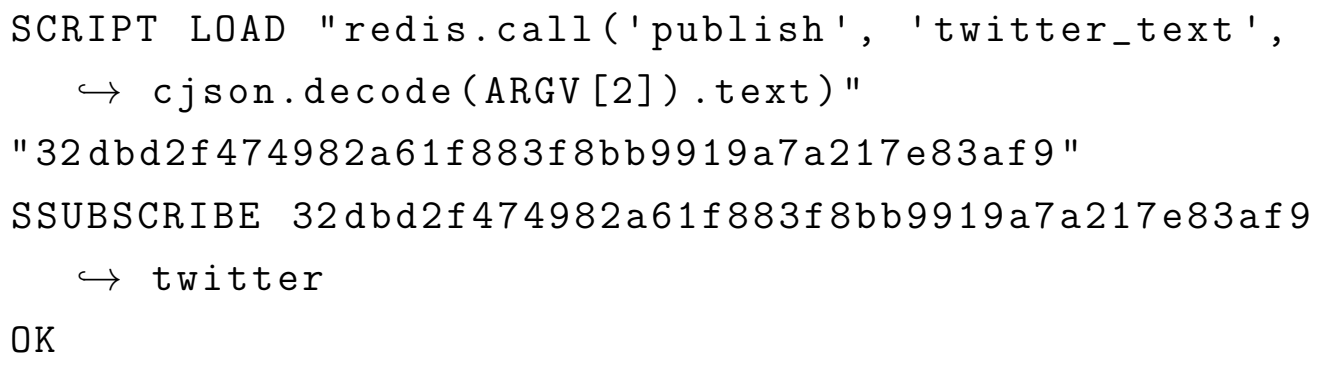

Para criar um canal de hashtags a partir do canal de texto, utilizamos o script "Extrai hashtags", registrado da seguinte maneira: 
Figura 5.4: Exemplo de uma DAG para processamento de stream de tweets, contabilizando as hashtags mais populares.

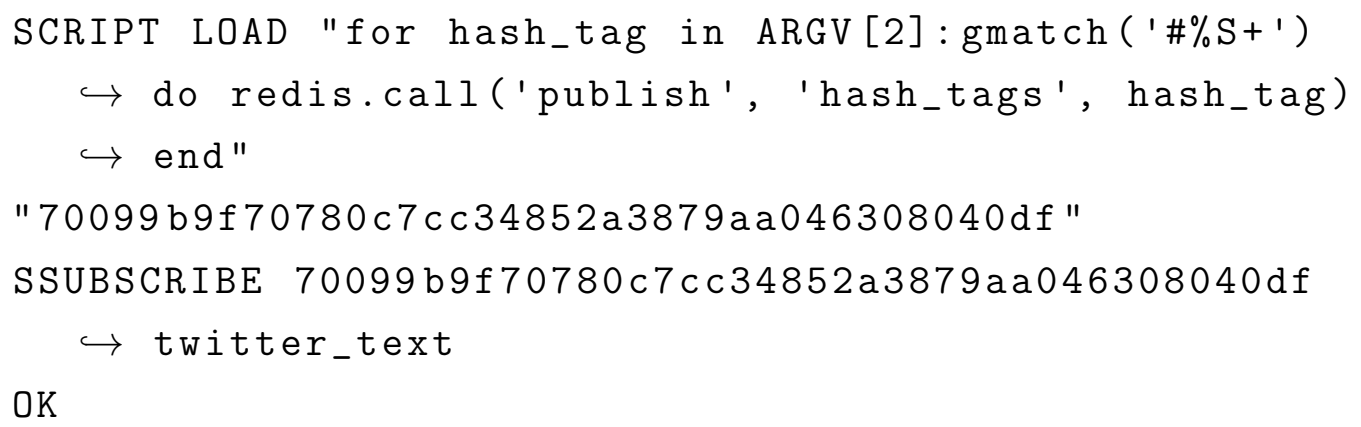

Finalmente, para contabilizar a quantidade de tweets para cada hashtag, registramos o script "Conta hashtags":

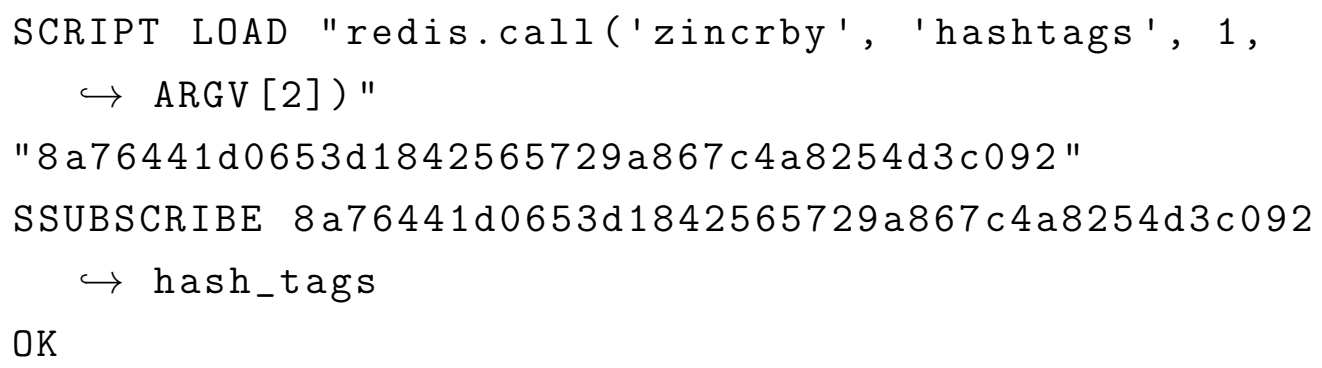


A quantidade de ocorrências de cada hashtag é gravada em uma estrutura de conjuntos ordenados. As cinco hashtags mais frequentes podem ser listadas através de um comando do Redis na chave de resultados:

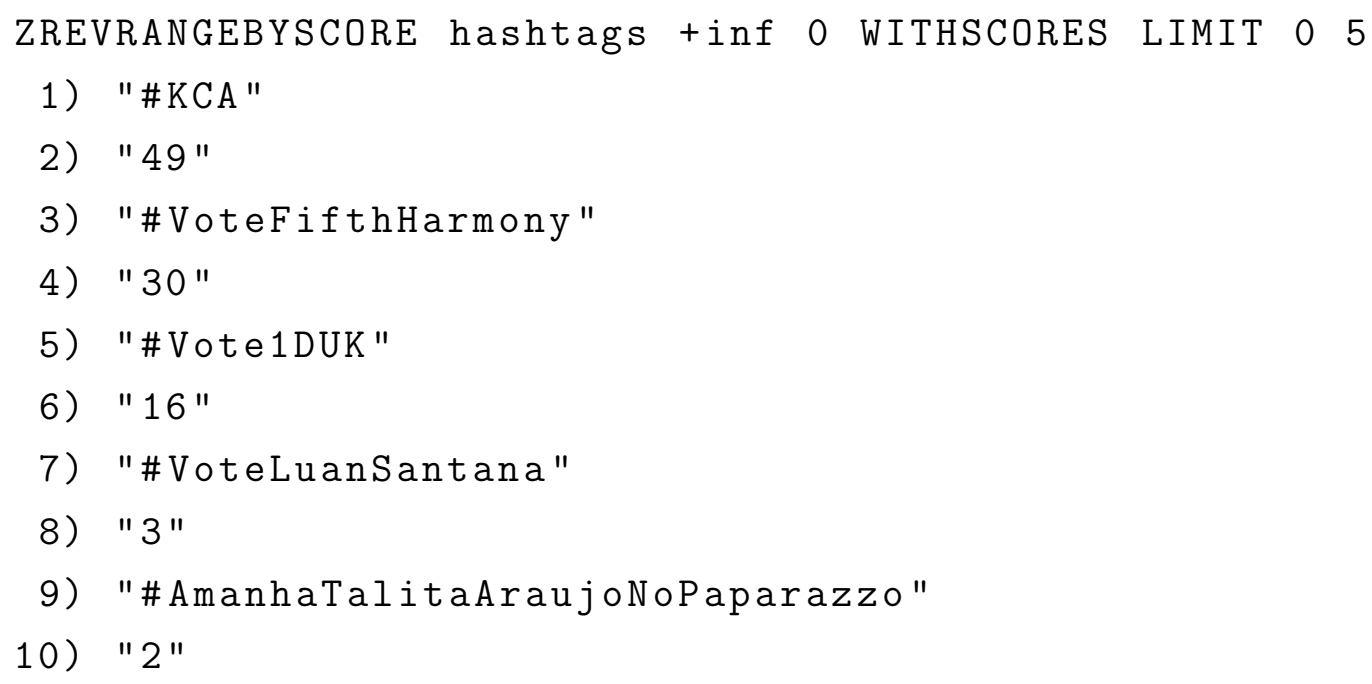

É possîvel criar um script monolítico que receba como argumento o texto de cada tweet e compute a frequência de cada hashtag. Preferimos decompor o problema em scripts menores que fazem uso dos canais para se comunicarem. Como vantagem dessa abordagem, clientes externos poderiam se registrar nos canais intermediários, que contém os textos e hashtags pré-processados.

O código que publica o stream no Redis, carrega os scripts e imprime as hashtags mais populares está disponível publicamente em https: //github.com/jbochi/twitter-stream. Executamos estes comandos no dia 28 de março de 2015 e a hashtag mais popular no Brasil era "\#KCA", relativa ao prêmio Kids' Choice Awards. Esta hashtag só passou a ser exibida pelo Twitter como um trending topic depois de aproximadamente uma hora. Rodamos novamente estes scripts no dia 02 de agosto de 2015 e as hashtags mais populares eram novamente relacionadas à televisão e entretenimento: "\#MPN" (concurso "Meus prêmios Nick"), "\#MTVHottest"(Concurso do canal MTV), "\#Los33"(um filme que estava estreiando no Brasil nesta data), "\#TataWerneck"(atriz), "\#ArthurAguiarNaDançaDosFamosos" (cantor em um programa de televisão).

Em nossos testes com o mesmo laptop utilizado no teste anterior, conseguimos processar 2050 mensagens/s com tempo de resposta médio de $24 \mathrm{~ms}$. Não podemos fazer uma comparação de desempenho com scripts bloqueantes ou com a implementação padrão do Redis porque somente os scripts assíncronos tem a capacidade de interagir com os canais PUB/SUB.

Nesta aplicação, utilizamos diferentes scripts para processar um mesmo canal de entrada, sem que o publicador precise ter ciência dos consumidores. Com o script que extrai hashtags, também validamos que é possível publicar 
mais de uma mensagem para uma única mensagem de entrada. Outras topologias também são possíveis. Por exemplo, podemos publicar mensagens em mais de um canal de saída ou inscrever o mesmo script em diferentes canais de entrada. 


\section{6 \\ Conclusão}

O objetivo principal deste trabalho foi investigar a adequação do modelo multi-tarefa $M: N$ em uma aplicação real de largo uso. Nossa contribuição se dá na implementação deste modelo no banco de dados Redis, adicionando o suporte a scripts paralelos de uma forma simples para o programador, que abstrai as dificuldades do escalonamento e da sincronização de tarefas. Conseguimos atingir este objetivo mantendo a compatibilidade com os scripts bloqueantes. Demonstramos a utilidade das extensões implementadas nos cenários de detecção de anomalias, aceleração de scripts e processamento de streams. Este resultado reforça o potencial de utilização do modelo multi-tarefa $M: N$ como uma ferramenta para possibilitar o paralelismo em linguagens dinâmicas de maneira eficiente e simples do ponto de vista do programador.

Em relação à implementação mono-tarefa padrão do banco de dados, observamos no nosso sistema ganhos significativos nos cenários explorados pelas aplicações desenvolvidas. No entanto, a implementação do modelo proposto introduziu necessidade de sincronização no processamento dos eventos de rede do Redis, o que causou perda de desempenho em alguns casos de uso comuns. Após o desenvolvimento deste trabalho, um branch de desenvolvimento do banco de dados Redis foi criado para permitir a liberação de memória de forma não bloqueante ${ }^{1}$. Essa implementação introduziu uma thread adicional para liberação de memória e, para que isso fosse possível, removeu o compartilhamento de objetos dos buffers de rede de cada cliente e de todos os comandos Redis, substituindo o compartilhamento por cópia dos dados. Essa alteração viabiliza a implementação de scripts assíncronos sem a necessidade de sincronização adicional que tivemos que introduzir para escrita na rede e potencialmente mais simples. No total, alteramos o código fonte do banco de dados em 12 arquivos e um total de 913 linhas de código em locais sensíveis.

Apesar dos resultados satisfatórios nos cenários propostos, em nossa implementação, existe contenção do lock global uma vez que todos os workers concorrem por ele para alteração de qualquer chave no Redis. Um possível trabalho futuro é implementar locks de menor granularidade, bloqueando

${ }^{1}$ http://antirez.com/news/93 
apenas as chaves que forem acessadas. Tal implementação é agora possível, uma vez que chaves Redis não mais compartilham dados internamente.

Outra melhoria anunciada no banco de dados$^{2}$ após o desenvolvimento de nossas alterações foi a possibilidade de depuração de scripts e replicação de scripts através da replicação do seu efeito e não do script, assim como fizemos com os scripts bloqueantes. Seria desejável que os scripts assíncronos também pudessem ser depurados da mesma forma.

A motivação deste trabalho era abstrair a complexidade da programação paralela em um pequeno nicho. Apesar das modificações no banco de dados terem sido pontuais, a implementação e depuração do programa para garantir um correto funcionamento do banco de dados em qualquer situação foi bastante díficil. Tivemos que lidar com diversas condições de corrida e experimentar estratégias diferentes de sincronização e escalonamento para obter um bom desempenho. Esta dificuldade só reforça nossa crença de que é necessário buscar abstrações mais simples e eficientes para que a programação paralela deixe de ser uma verdadeira arte e entre no alcance de um público maior de desenvolvedores. 


\section{7 Referências Bibliográficas}

ADYA, A. et al. Cooperative task management without manual stack management. In: Proceedings of the General Track of the Annual Conference on USENIX Annual Technical Conference. Berkeley, CA, USA: USENIX Association, 2002. (ATEC '02), p. 289-302. ISBN 1-880446-00-6. Disponível em: $<$ http://dl.acm.org/citation.cfm?id $=647057.713851>$.

AKIDAU, $T$. et al. Millwheel: Fault-tolerant stream processing at internet scale. Proc. VLDB Endow., VLDB Endowment, v. 6, n. 11, p. 1033-1044, ago. 2013. ISSN 2150-8097. Disponível em: <http://dx.doi.org/10.14778/2536222.2536229>.

ANDERSON, T. E. et al. Scheduler activations: Effective kernel support for the user-level management of parallelism. SIGOPS Oper. Syst. Rev., ACM, New York, NY, USA, v. 25, n. 5, p. 95-109, set. 1991. ISSN 0163-5980. Disponível em: $<$ http://doi.acm.org/10.1145/121133.121151>.

ANDREWS, G. R. Concurrent Programming: Principles and Practice. Redwood City, CA, USA: Benjamin-Cummings Publishing Co., Inc., 1991. ISBN 0-8053-0086-4.

BEHREN, R. von; CONDIT, J.; BREWER, E. Why events are a bad idea (for high-concurrency servers). In: Proceedings of the 9th Conference on Hot Topics in Operating Systems - Volume 9. Berkeley, CA, USA: USENIX Association, 2003. (HOTOS'03), p. 4-4. Disponível em: $<$ http://dl.acm.org/citation.cfm?id=1251054.1251058>.

BROOKS JR., F. P. No silver bullet - essence and accidents of software engineering. IEEE Computer, IEEE Computer Society Press, Los Alamitos, CA, USA, v. 20, n. 4, p. 10-19, abr. 1987. ISSN 0018-9162. Disponível em: <http://dx.doi.org/10.1109/MC.1987.1663532>.

CHANDOLA, V.; BANERJEE, A.; KUMAR, V. Anomaly detection: A survey. ACM Computing Surveys, ACM, New York, NY, USA, v. 41, n. 3, p. 15:1-15:58, jul. 2009. ISSN 0360-0300. Disponível em: <http://doi.acm.org/10.1145/1541880.1541882>. 
HALLER, P.; ODERSKY, M. Actors that unify threads and events. In: Proceedings of the 9th International Conference on Coordination Models and Languages. Berlin, Heidelberg: Springer-Verlag, 2007. (COORDINATION'07), p. 171-190. ISBN 978-3-540-72793-4. Disponível em: $<$ http://dl.acm.org/citation.cfm?id=1764606.1764620>.

HALLER, P.; ODERSKY, M. Scala actors: Unifying thread-based and event-based programming. Theorical Computer Science, Elsevier Science Publishers Ltd., Essex, UK, v. 410, n. 2-3, p. 202-220, fev. 2009. ISSN 0304-3975. Disponível em: <http://dx.doi.org/10.1016/j.tcs.2008.09.019>.

HERLIHY, M. et al. Software transactional memory for dynamic-sized data structures. In: Proceedings of the Twenty-second Annual Symposium on Principles of Distributed Computing. New York, NY, USA: ACM, 2003. (PODC '03), p. 92-101. ISBN 1-58113-708-7. Disponível em: $<$ http://doi.acm.org/10.1145/872035.872048>.

HICKEY, R. The Clojure programming language. In: Proceedings of the 2008 Symposium on Dynamic Languages. New York, NY, USA: ACM, 2008. (DLS '08), p. 1:1-1:1. ISBN 978-1-60558-270-2. Disponível em: <http://doi.acm.org/10.1145/1408681.1408682>.

HOARE, C. A. R. Communicating sequential processes. Communications of the ACM, ACM, New York, NY, USA, v. 21, n. 8, p. 666-677, ago. 1978. ISSN 0001-0782. Disponível em: <http://doi.acm.org/10.1145/359576.359585>.

IERUSALIMSCHY, R. Programming in Lua. 3rd. ed. [S.I.]: Lua.Org, 2013. 347 p. ISBN 859037985X, 9788590379850.

KARGER, D. et al. Consistent hashing and random trees: Distributed caching protocols for relieving hot spots on the world wide web. In: Proceedings of the Twenty-ninth Annual ACM Symposium on Theory of Computing. New York, NY, USA: ACM, 1997. (STOC '97), p. 654-663. ISBN 0-89791-888-6. Disponível em: <http://doi.acm.org/10.1145/258533.258660>.

LISKOV, B. Distributed programming in Argus. Communications of the ACM, ACM, New York, NY, USA, v. 31, n. 3, p. 300-312, mar. 1988. ISSN 0001-0782. Disponível em: <http://doi.acm.org/10.1145/42392.42399>.

MCCRACKEN, D. Posix threads and the Linux kernel. In: Proceedings of the Ottawa Linux Symposium. Ottawa, Canada: Ottawa Linux Symposium, 2002. p. 330-337. 
MCKENNEY, P. E. Is parallel programming hard, and, if so, what can you do about it? 2011.

MICROSOFT. C\# Programming Guide. 2014. Disponível em: $<$ http://msdn.microsoft.com/en-us/library/67ef8sbd.aspx >.

$\begin{array}{llll}\text { MICROSOFT. } & \text { User-Mode } & \text { Scheduling. }\end{array}$

Disponível em: <https://msdn.microsoft.com/en-

us/library/windows/desktop/dd627187(v=vs.85).aspx $>$.

MOURA, A. L. D.; IERUSALIMSCHY, R. Revisiting coroutines. ACM Transactions on Programming Languages and Systems, ACM, New York, NY, USA, v. 31, n. 2, p. 6:1-6:31, fev. 2009. ISSN 0164-0925. Disponível em: $<$ http://doi.acm.org/10.1145/1462166.1462167>.

OUSTERHOUT, J. Why threads are a bad idea (for most purposes). In: Presentation given at the 1996 Usenix Annual Technical Conference. San Diego, CA, USA: USENIX Association, 1996. v. 5.

PEREIRA, R. et al. Cloud based real-time collaborative filtering for item-item recommendations. Computers in Industry, Elsevier, v. 65, n. 2, p. 279-290, 2014.

SKYRME, A.; RODRIGUEZ, N.; IERUSALIMSCHY, R. Exploring Lua for concurrent programming. v. 14, n. 21, p. 3556-3572, 2008.

SKYRME, A.; RODRIGUEZ, N.; IERUSALIMSCHY, R. Scripting multiple CPUs with safe data sharing. Software, IEEE, v. 31, n. 5, p. 44-51, Sept 2014. ISSN 0740-7459.

SUTTER, $\mathrm{H}$. The free lunch is over: A fundamental turn toward concurrency in software. Dr. Dobb's journal, v. 30, n. 3, p. 202-210, 2005.

TAnenbaum, A. S.; STEEN, M. v. Distributed Systems: Principles and Paradigms (2nd Edition). Upper Saddle River, NJ, USA: Prentice-Hall, Inc., 2006. ISBN 0132392275.

TOSHNIWAL, A. et al. Storm@twitter. In: Proceedings of the 2014 ACM SIGMOD International Conference on Management of Data. New York, NY, USA: ACM, 2014. (SIGMOD '14), p. 147-156. ISBN 978-1-4503-2376-5. Disponível em: <http://doi.acm.org/10.1145/2588555.2595641>.

VIRDING, R.; WIKSTRöM, C.; WILLIAMS, M. Concurrent Programming in Erlang (2nd Edition). Hertfordshire, UK, UK: Prentice Hall International (UK) Ltd., 1996. ISBN 0-13-508301-X. 
WALKER, E. F.; FLOYD, R.; NEVES, P. Asynchronous remote operation execution in distributed systems. In: IEEE. Distributed Computing Systems, 1990. Proceedings., 10th International Conference on. Paris, France, 1990. p. 253259.

WANG, C. et al. Statistical techniques for online anomaly detection in data centers. In: IEEE. Integrated Network Management (IM), 2011 IFIP/IEEE International Symposium on. Dublin, Ireland, 2011. p. 385-392.

YUE, Y. How Twitter Uses Redis To Scale - 105TB RAM, 39MM QPS, 10,000+ Instances. 2014. Disponível em: $<$ http://highscalability.com/blog/2014/9/8/how-twitter-uses-redis-to-scale105tb-ram-39mm-qps-10000-ins.html>. 


\section{A \\ Exemplo de sessão no terminal}

Através da interface de linha de comando do Redis, é possível fazer experimentação e testes não automatizados. Um exemplo de sessão no terminal demonstrando os comandos básicos do Redis e também os de scripting está abaixo. Os comandos executados estão em negrito e o retorno está em fonte padrão.

$\% . /$ redis $-\mathrm{cli}$

redis $>$ ping

PONG

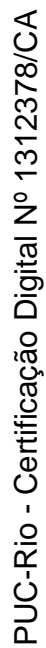

redis $>$ SET nome juarez

OK

redis $>$ GET nome

"juarez"

redis $>$ incr mycounter

(integer) 1

redis $>$ incr mycounter

(integer) 2

redis $>$ EVAL " return \{KEYS[1],KEYS[2],ARGV[1],ARGV[2]\}" 2

$\hookrightarrow$ key 1 key 2 first second

1) "key1"

2) "key2"

3) "first"

4) "second"

redis $>$ EVAL "return redis.call ('get ', 'mycounter ')" 0

$" 2 "$

redis > EVAL "return redis.call ('set ',KEYS[1], 'bar ')" 1 foo

OK

redis > GET foo

"bar"

redis > SCRIPT LOAD " return 1"

"e0e1f9fabfc $9 \mathrm{~d} 4800 \mathrm{c} 877 \mathrm{a} 703 \mathrm{~b} 823 \mathrm{ac} 0578 \mathrm{ff} 8 \mathrm{db} "$

redis $>$ SCRIPT EXISTS

$\hookrightarrow$ e0e1f9fabfc $9 \mathrm{~d} 4800 \mathrm{c} 877 \mathrm{a} 703 \mathrm{~b} 823 \mathrm{ac} 0578 \mathrm{ff} 8 \mathrm{db}$

1) (integer) 1 
redis $>$ EVALSHA e0e1f9fabfc 9 d $4800 \mathrm{c} 877 \mathrm{a} 703 \mathrm{~b} 823 \mathrm{ac} 0578 \mathrm{ff} 8 \mathrm{db} \quad 0$ (integer) 1

redis $>$ SCRIPT FLUSH

OK

redis $>$ SCRIPT EXISTS

$\hookrightarrow$ e0e 1 f 9 fabfc $9 \mathrm{~d} 4800 \mathrm{c} 877 \mathrm{a} 703 \mathrm{~b} 823 \mathrm{ac} 0578 \mathrm{ff} 8 \mathrm{db}$

1) (integer) 0

redis $>$ EVALSHA e0e1f9fabfc $9 \mathrm{~d} 4800 \mathrm{c} 877 \mathrm{a} 703 \mathrm{~b} 823 \mathrm{ac} 0578 \mathrm{ff} 8 \mathrm{db} \quad 0$

(error) NOSCRIPT No matching script. Please use EVAL. 


\section{B}

\section{Algoritmo de quadratura adaptativa no Redis}

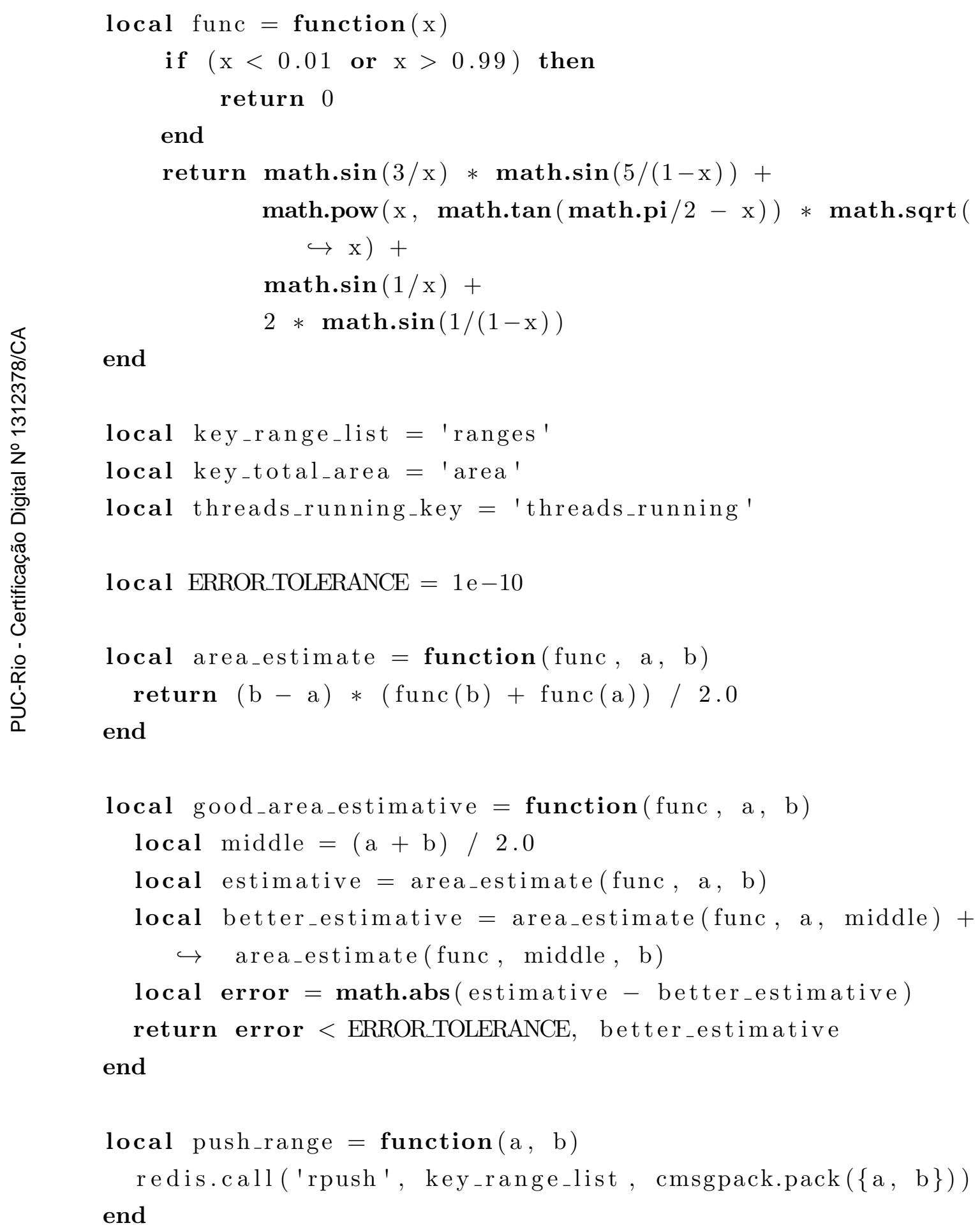



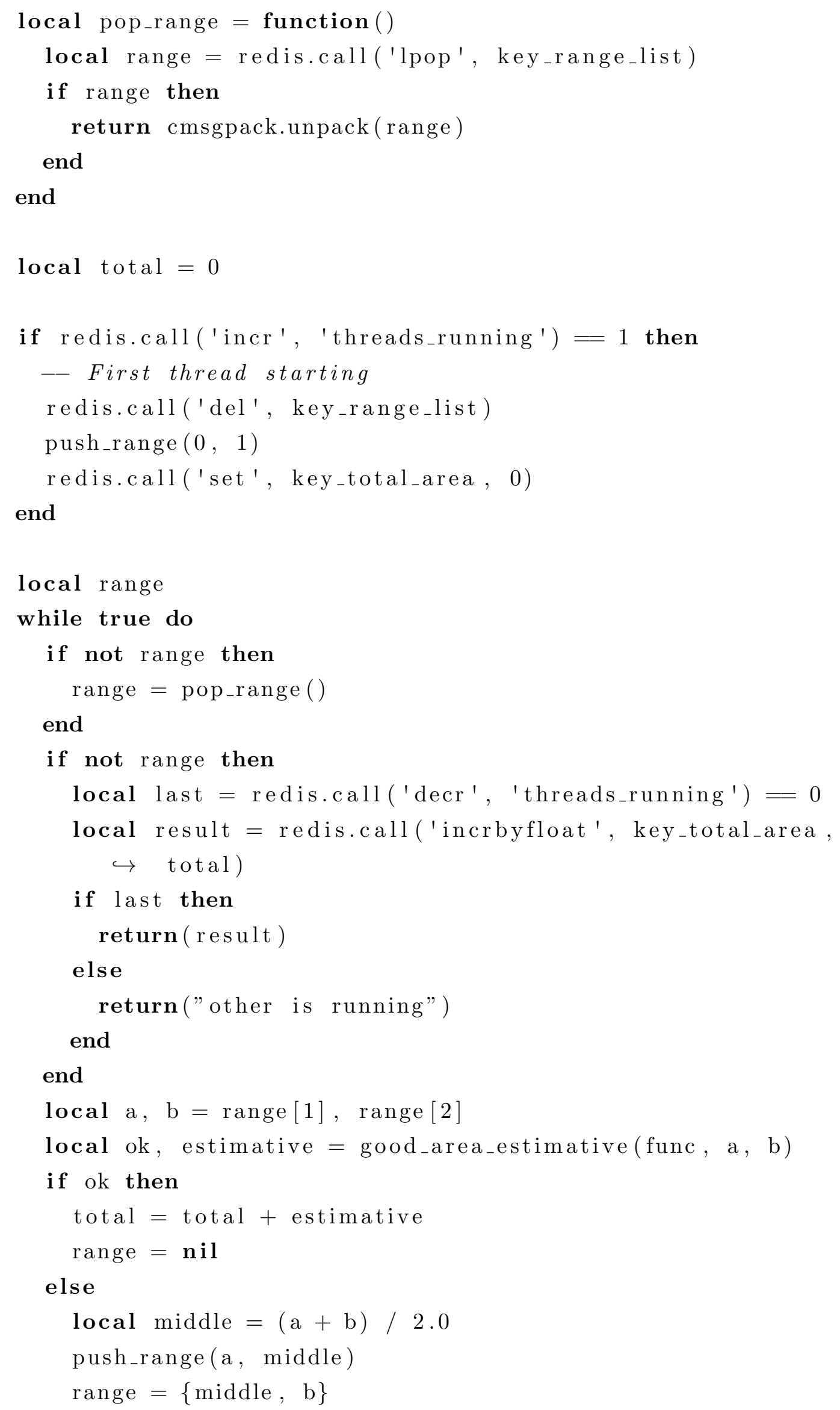
end

end 